\title{
The Role of Rock Matrix Permeability in Controlling Hydraulic Fracturing in Sandstones
}

\author{
Marco Fazio $^{1}\left(\mathbb{D} \cdot\right.$ Peter Ibemesi $^{2} \cdot$ Philip Benson $^{2} \cdot$ Diego Bedoya-González $^{1,3} \cdot$ Martin Sauter $^{1}$
}

Received: 31 July 2020 / Accepted: 15 July 2021 / Published online: 30 July 2021

(c) The Author(s) 2021

\begin{abstract}
A concomitant effect of a hydraulic fracturing experimenting is frequently fluid permeation into the rock matrix, with the injected fluid permeating through the porous rock matrix (leak-off) rather than contributing to the buildup of borehole pressure, thereby slowing down or impeding the hydro-fracturing process. Different parameters, such as low fluid viscosity, low injection rate and high rock permeability, contribute to fluid permeation. This effect is particularly prominent in highly permeable materials, therefore, making sleeve fracturing tests (where an internal jacket separates the injected fluid in the borehole from the porous rock matrix) necessary to generate hydraulic fractures. The side effect, however, is an increase in pressure breakdown, which results in higher volume of injected fluid and in higher seismic activity. To better understand this phenomenon, we report data from a new comparative study from a suite of micro-hydraulic fracturing experiments on highly permeable and on low-permeability rock samples. Experiments were conducted in both sleeve fracture and direct fluid fracture modes using two different injection rates. Consistent with previous studies, our results show that hydraulic fracturing occurred only with low permeation, either due to the intrinsic low permeability or due to the presence of an inner silicon rubber sleeve. In particular, due to the presence of quasi-impermeable inner sleeve or borehole skin in the sleeve fracturing experiment, fracturing occurs, with the breakdown pressure supporting the linear elastic approach considering poroelastic effects, therefore, with low stress drop and consequently low microseismicity. Rock matrix permeability also controls the presence of precursory Acoustic Emission activity, as this is linked to the infiltration of fluids and consequent expansion of the pore space. Finally, permeability is shown to mainly control fracturing speed, because the permeation of fluid into the newly created fracture via the highly permeable rock matrix slows down its full development. The application of these results to the field may help to reduce induced seismicity and to conduct well stimulation in a more efficient way.
\end{abstract}

Keywords Permeability $\cdot$ Hydraulic fracturing $\cdot$ Acoustic emissions $\cdot$ Fracture propagation speed $\cdot$ Fluid permeation $\cdot$ Leakoff

\section{List of Symbols}

$P_{\mathrm{b}} \quad$ Breakdown pressure

$S_{\mathrm{h}} \quad$ Minor horizontal stress

$S_{\mathrm{H}} \quad$ Major horizontal stress

$\sigma_{\mathrm{T}} \quad$ Tensile strength

$P_{0} \quad$ Pore pressure

$\alpha \quad$ Biot poroelastic coefficient

Marco Fazio

marco.fazio@uni-goettingen.de

1 Department of Applied Geology, University of Göttingen, Goldschmidtstraße 3, 37077 Göttingen, Germany

2 Rock Mechanics Laboratory, University of Portsmouth, Portsmouth PO1 3QL, UK

3 Department of Geography and Geology, University of Salzburg, 5020 Salzburg, Austria

$\begin{array}{ll}\nu & \text { Poisson's ratio } \\ \sigma_{\mathrm{ax}} & \text { Axial stress } \\ \sigma_{\mathrm{r}} & \text { Confining pressure } \\ \sigma_{\mathrm{diff}} & \text { Differential stress } \\ p_{\mathrm{inj}} & \text { Injection pressure } \\ k_{\mathrm{w}} & \text { Wall permeability } \\ k_{\mathrm{wc}} & \text { Critical wall permeability } \\ v_{\mathrm{inj}} & \text { Injected volume } \\ \varepsilon_{\mathrm{ax}} & \text { Axial strain } \\ \varepsilon_{\mathrm{rNS}} & \text { Radial strain measured north-south } \\ \varepsilon_{\mathrm{rEW}} & \text { Radial strain measured east-west }\end{array}$




\section{Introduction}

Hydraulic fracturing is a well-stimulation technique with the reservoir rock to be fractured by the injection of pressurized liquids. It is employed in the oil and gas industry to produce hydrocarbons from tight reservoirs (including the extraction of shale gas), as well as to improve the permeability of geothermal reservoirs for enhanced, fluid and heat circulation between injection and production wells.

Fluid is injected into the reservoir rock through a borehole and, to fracture the surrounding rock, must be pressurized to reach breakdown pressure $\left(P_{\mathrm{b}}\right)$. Considering a vertical borehole, in a linear elastic approach (Hubbert and Willis 1957; Jaeger et al. 2009; Brenne et al. 2013; Stoeckhert et al. 2014), with a defect-free, non-porous and impermeable rock matrix surrounding the borehole,

$P_{\mathrm{b}}=3 S_{\mathrm{h}}-S_{\mathrm{H}}+\sigma_{\mathrm{T}}$,

where $S_{\mathrm{H}}$ and $S_{\mathrm{h}}$ are major and minor horizontal stresses and $\sigma_{\mathrm{T}}$ is the hydraulic tensile strength. The only parameter intrinsic to the rock mass is its tensile strength. However, rocks are far from ideal materials, and instead are characterized by a ubiquitous network of fractures and pores. With these defects mostly isolated and a poor connectivity, hence with a low permeability, but saturated with pore fluid at pressure $P_{0}$, then Eq. 2 applies

$P_{\mathrm{b}}=3 S_{\mathrm{h}}-S_{\mathrm{H}}+\sigma_{\mathrm{T}}-P_{0}$.

When, instead, the rock is both porous and permeable, poroelastic effects (Haimson and Fairhurst 1969; Jaeger et al. 2009; Stoeckhert et al. 2014) must be included in Eq. 1, such as

$P_{\mathrm{b}}=\frac{3 S_{\mathrm{h}}-S_{\mathrm{H}}+\sigma_{\mathrm{T}}}{2-\alpha \frac{1-2 v}{1-v}}-P_{0}$.

Here, $P_{\mathrm{b}}$ depends also on two additional rock properties: the Poisson's ratio $(\nu)$ and the Biot poroelastic coefficient $(\alpha)$, with the latter directly depending on rock porosity and its geometry (Biot and Willis 1957).

Once fracturing commences, fluid leak-off of the fracturing fluid into the adjacent rock matrix may occur depending on the permeability of the rock matrix and the presence of natural fractures. Consequently, this influences the stress regime surrounding the tip of the induced fracture, affecting its width and aperture. The presence of pre-existing fracture has a major role, as it has been observed that this increases threefold the leak-off rate (Ghaderi et al. 2019).

Over the last 50 years, since the pioneering work of Hubbert and Willis (1957), several experimental studies were conducted to understand the physics behind hydraulic fracturing, many focusing on the role of rock porosity and its geometry. Considering the nature of laboratory experiments, where a different set of parameters can be measured, or even controlled, to replicate natural phenomena at a smaller scale, the outcomes of these provided pertinent information. In particular the work of Haimson and Fairhurst (1969) demonstrated how experiments could be used to test experimentally the theories proposed for the generation of hydraulic fractures which has an extensive literature. The Haimson and Fairhurst experiments induced hydraulic fractures on five rock types for different experimental conditions (e.g. confining pressure, pressurization rate, borehole diameter, and type of packer). Samples were both cylindrical and cubical, with the fluid injected through the packer within a centrally drilled borehole. Among the results, it was found that the penetration of injected fluid through the rock matrix affects the existing criteria for hydraulic fracturing, which required two additional parameters (see Eq. 3) for permeable rocks. Therefore, new data have been reported to understand these effects by testing and comparing rocks with different textural and hydraulic properties (Brenne et al. 2013; Stoeckhert et al. 2014; Stanchits et al. 2015; He et al. 2016; Lin et al. 2018; Molenda et al. 2013; Chen et al. 2018; Rummel 1987; Chitrala et al. 2011), as well as using synthetic/engineered materials such as concrete (Meng and De Pater 2011; Ha et al. 2017).

Infiltration through the rock matrix during hydraulic fracturing may occur also in low-permeability rock, when the injection rate is not sufficiently high, allowing the injected fluid to saturate the sample instead of pressurizing the borehole (Zhuang et al. 2018). Regardless the cause, fluid infiltration makes the fracturing process less efficient. To tackle this effect, either the injection rate must increase (Ito and Hayashi 1991; Zhuang et al. 2018) to build up pressure more rapidly, or the borehole must be physically separated from the surrounding rock matrix (Brenne et al. 2013; Stoeckhert et al. 2014, 2015, 2016; Zhuang et al. 2018; Vinciguerra et al. 2004; Molenda et al. 2015; Pradhan et al. 2014; Ito and Hayashi 1991). However, both solutions ultimately carry a side effect, i.e. an increased micro-seismic activity.

When the injected fluid can interact with the rock matrix (so called Fluid Fracturing, FF, mode) and the fracture is created, the injected pressure is continually transferred to the crack tip, promoting an unstable propagation. This requires no additional pressure compared to the pressure at fracture nucleation, with a relative low stress drop. When, instead, the injected fluid is not allowed to interact with the rock matrix (so called Sleeve Fracturing, SF, mode), once the fracture nucleates, fluid will not provide pressure at the crack tip. Hence the fracture propagates only with increasing borehole pressure, yielding stable propagation (Brenne et al. 2013; Vinciguerra et al. 2004). The stress drop is higher and consequently results in relative higher seismic activity. Occurrence of anomalous earthquakes is a serious problem 
near a hydro-fracturing-based energy plant and an increased seismic activity may halt industrial operations (Majer et al. 2007).

Seismic activity at the laboratory scale is generated by the nucleation and extension of micro-cracks generating elastic strain waves, which are called Acoustic Emissions (AEs). Since its first employment in monitoring micro-crack formations during hydraulic fracturing tests (Lockner and Byerlee 1977), AE monitoring has been extensively used to monitor and control the formation and propagation of fractures (Vinciguerra et al. 2004; Naoi et al. 2018; Ishida et al. 1998; Stanchits et al. 2014). Analysis of the AE data span from simple rate, amplitude and energy distribution to more complex location detection and source component determination. It has been found that $\mathrm{AE}$ activity is almost absent prior to failure in FF experiments, while it increases exponentially well before failure in SF mode (Brenne et al. 2013; Ito and Hayashi 1991). In terms of location and source components, only SF experiments managed to generate localizable AE due to the occurrence of a stable propagation (Molenda et al. 2015).

Although the porosity and its geometry play an important role in controlling the hydraulic fracturing process through fluid infiltration, only few attempts (Brenne et al. 2013; Stoeckhert et al. 2014; Zhuang et al. 2018; Molenda et al. 2015; Ito and Hayashi 1991) have compared the results of experiments performed in FF and SF mode. Ito and Hayashi (1991) performed uniaxial experiments on cubic samples of two different, low-permeable andesites, finding a dependence of breakdown pressure on wellbore diameter and pressurization rate. In particular, a high-pressurization rate is effective in reducing fluid permeation only with slightly permeable rocks, and consequently increases the breakdown pressure. Brenne et al. (2013) tested six different rock types, changing confining pressures and borehole diameters, whose results suggest a different hydraulic tensile strength for the same rock type and a sixfold increase of the breakdown pressure (likely due to the presence of relatively long cracks) depending on the presence of the inner sleeve. Stoeckhert et al. (2014) performed hydraulic fracturing tests in triaxial conditions on seven rock types, varying confining pressure and specimen's length, and comparing the experimental results with numerical modelling. Estimation of the breakdown pressure in SF requires only the fracture toughness of the material, while in FF also the intrinsic initial fracture length is needed. For Molenda et al. (2015) the presence of the inner sleeve simulates the injection of an infinitively high viscous fluid. Furthermore, this enables the stable propagation of bi-winged fractures, with a characteristic penny shape, and a reliable AE monitoring capable of tracing the fracture front. However, cases of rapid fracture propagation were also observed in SF mode, due to the presence of unfavourable-oriented pre-existing fracture within the rock sample. Zhuang et al. (2018) recorded higher AE energy released during fracturing in SF mode, with the resultant fractures being straighter with less branching.

The AE analysis of the above-mentioned studies is mostly limited to the hit rate statistics, with no further comparison of amplitudes, energy, location or source component. To improve efficiency and to reduce seismic activity, we analyse mechanical and AE data of experiments in SF and FF for highly porous and permeable rock as well as in FF in rock with lower porosity and permeability. By injecting viscous oil inside the borehole, we induced hydraulic fracturing only with moderate or absent infiltration. We monitored and analysed both $\mathrm{AE}$ and mechanical data, which provided us with information on fracture nucleation timing and fracture propagation direction as well as full saturation and pressure equilibrium, for cases with no fracture being generated. The aim is to compare experimental set-ups with (i) no infiltration, (ii) medium infiltration and (iii) high infiltration and so to understand how the interaction between the injected fluid and rock matrix control the eventual nucleation and propagation of hydraulic fractures.

\section{Equipment and Methods}

\subsection{Sample Preparation}

Hydraulic fracturing experiments are performed on cylindrical samples of Bentheim Sandstone (hereafter BS) and Crab Orchard Sandstone (COS). BS is a Lower Cretaceous formation, deposited in shallow marine conditions in the Lower Saxony Basin (north-west Germany). It is a quartzarenite, with up to $97 \%$ of quartz, completed by feldspar, kaolinite, glauconite and lithic fragments (Fig. 1A). Wellsorted medium-fine sand particles constitute the rock matrix, while same-size, angular and well-connected pores form the pore space. Porosity ranges between 20 and 26\%, and permeability between 1000 and $2000 \mathrm{mD}$ (Benson et al. 2005; Stück et al. 2013; Peksa et al. 2015; Dubelaar and Nijland 2016; Ma and Haimson 2016; Saenger et al. 2016; Rück et al. 2017). The Biot coefficient $(\alpha)$, a crucial poroelastic parameter, of 0.95 was calculated for quasi ambient pressure, while it decreases to ca. 0.61-0.68 at an effective pressure of $35 \mathrm{MPa}$ (Blöcher et al. 2014). The tensile strength $\left(\sigma_{t}\right)$, calculated by the Brazilian Disc method, is $1.9 \mathrm{MPa}$ (Rück et al. 2017), while the Poisson's ratio $(\nu)$ varies between 0.2 and 0.25 (Jasinski et al. 2015; Peksa et al. 2015; Rück et al. 2017). Due to its mineral composition and grain size distribution, as well as the lateral continuity, homogeneity at the block scale and pore space geometry, BS is considered a reference rock in standard laboratory experiments and, therefore, extensively tested in triaxial conditions as reservoir in oil and gas, geothermal energy and carbon dioxide storages 

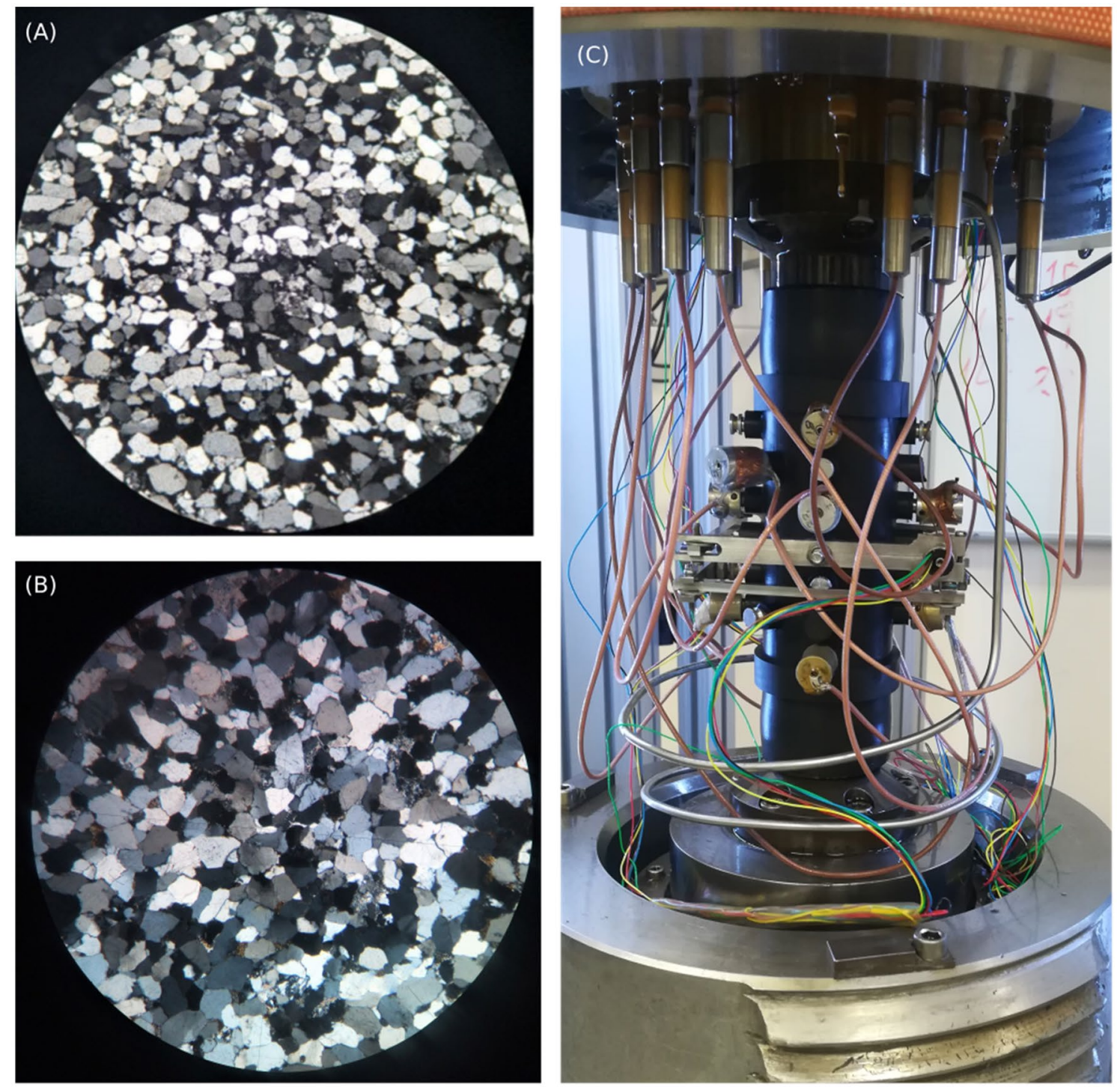

(D)
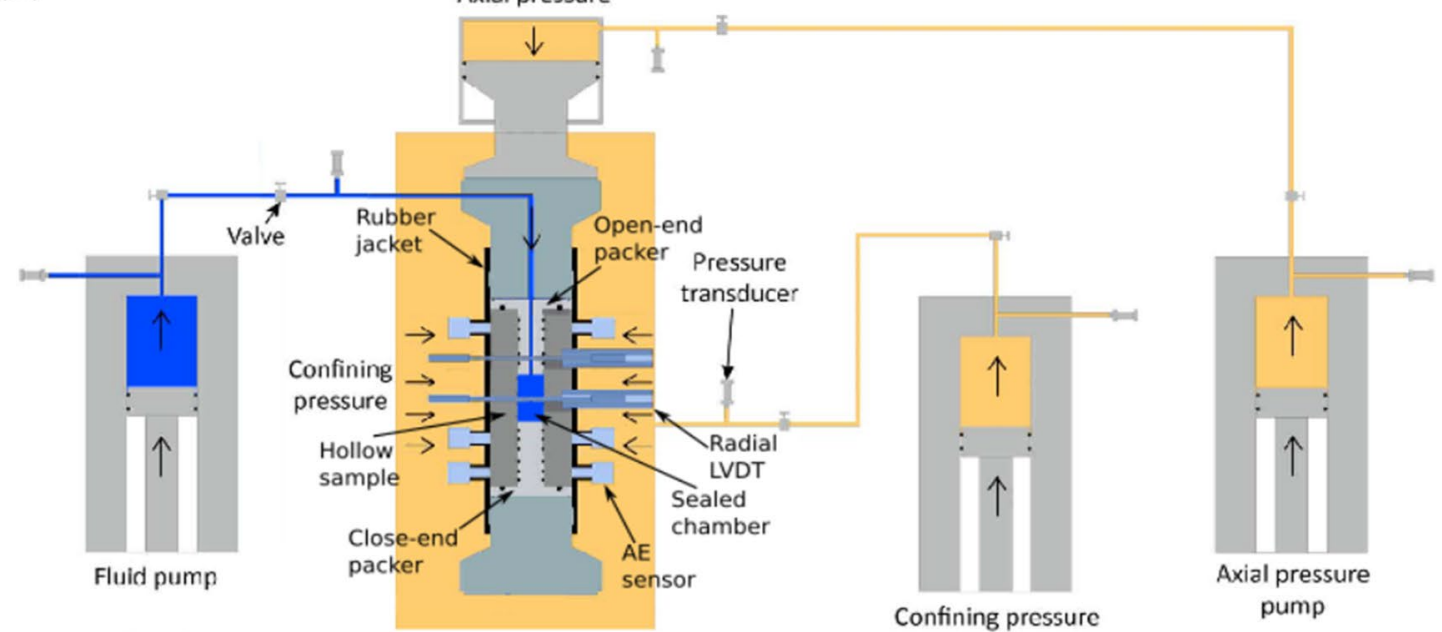
4Fig. 1 A BS and B COS under the microscope in cross-polarized light $(4 \times)$. Both rocks show high content of quartz crystals, with BS having finer grain size and larger pore space. $\mathbf{C}$ The sample assembly within the triaxial cell, showing the AE sensor array (grey cylinders plugged to the black rubber jacket) and the radial cantilevers (grey long bars plugged in the centre of the jacket). D Sketch of the main components of the triaxial apparatus and the sample assembly ( modified from Gehne and Benson 2019)

studies (Ma and Haimson 2016; Peksa et al. 2015; Pimienta et al. 2017). Since bedding planes are hardly visible (Benson et al. 2005; Ma and Haimson 2016), all BS specimens were obtained from the same block, in a single core run.

COS conversely, can be described as a low porosity, highly anisotropic sandstone from fluvial deposits of the Cumberland Plateau (Tennessee, USA). The material is fine grained and cross bedded (evidence of fluvial process) with a porosity of approximately $5 \%$ and a low permeability in the range of micro-Darcy $\left(10^{-18} \mathrm{~m}^{2}\right)$ (Benson et al. 2003). The grain material can be described as subhedral to subrounded with predominantly quartz ( $>85 \%)$ with some feldspar and lithic materials cemented by sericitic clay (Fig. 1B) (Benson et al. 2006; Gehne and Benson 2017). Tensile strength $\left(\sigma_{t}\right)$, calculated by the Brazilian Disc method, is $8.6 \mathrm{MPa}$ (parallel to bedding) and $9.8 \mathrm{MPa}$ (perpendicular to bedding) (Gehne et al. 2019). Due to the low permeability and porosity, COS can be considered as a tight sandstone suitable for laboratory simulation of a hydraulic fracture processes in unconventional (tight sand) hydrocarbon stimulation (Gehne and Benson 2017).

Cylindrical samples of approximately $93 \mathrm{~mm}$ (length) by $40 \mathrm{~mm}$ (diameter) were cored using a standard diamond tipped coring drill. Through a lathe equipped with a cross-cutting diamond grinding disk, the end faces of the samples were ground so that the faces are flat and parallel to $\pm 0.01 \mathrm{~mm}$. For hydraulic fracturing experiments, a borehole of $12.8 \mathrm{~mm}$ is drilled through the center of the long axis, generating hollow cylinders.

As per Gehne and Benson (2019), the sample assembly consisted of the hollow rock cylinder, a close-end, solid steel packer on the bottom of the sample, an open-end, hollowed steel packer to top and a FKM-B rubber jacket (Sammonds 1999; Fazio et al. 2019) encasing the sample. The openend packer allowed the injection of fluids within and further pressurization of a central sealed chamber (encased between the ends of the packer and borehole wall), while the rubber jacket separated the sample assembly from the confining medium and hosted rubber ports where Acoustic Emissions (AEs) sensors and radial strain cantilevers are plugged in (Fig. 1C) (Gehne and Benson 2019).

To reduce the permeability of the borehole wall in BS samples, and, therefore, retain the injected fluid during the pressurization, two specimens of BS (BS4 and BS8) have their inner wall painted with a mixture of transparent platinum cure silicone rubber (thereafter inner sleeve or borehole skin) that solidifies within a few minutes of its application. Compared to the FKM-B rubber (outer) jacket this inner sleeve was softer, so that placing a homogeneous and constant thickness could not be guaranteed. This step was not needed with COS as it is natural proxy of the unconventional reservoirs with low permeability, naturally retaining injection fluid by inhibiting fluid permeation during pressurization.

\subsection{Experimental Procedure}

The experiments were performed in a servo-controlled triaxial apparatus installed at the Rock Mechanics Laboratory at the University of Portsmouth (UK) (Fig. 1D). A detailed description of the apparatus is found in Fazio (Fazio 2017).

In addition to a conventional $1 \mathrm{~Hz}$ monitoring system recording mechanical data, pressures, injected volumes, flow rates and axial displacements, an auxiliary high-speed $5 \mathrm{kHz}$ data acquisition system was installed to record details of pore pressure, and axial and radial displacements (Fazio 2017; Gehne and Benson 2019; Fazio et al. 2017). In particular, while axial displacement was recorded via two external LVDTs (Linear Variable Differential Transformers), the radial displacement was monitored through two internal LVDTs, in a cantilever arrangement, oriented $90^{\circ}$ to each other, fixed in the ports of the rubber jacket and measuring the displacements midway of the sample's length (Fig. 1C, D) (Gehne and Benson 2019).

$\mathrm{AE}$ monitoring was achieved through an array of 12 piezoelectric Lead Zirconate Titanate sensors, with central resonating frequency at $1 \mathrm{MHz}$. The AE sensors were plugged into dedicated ports in the rubber jacket covering the lateral surface of the rock cylinder. The AE sensors were distributed arbitrarily around the sample, with seven sensors positioned above the radial cantilevers and five sensors below them (Fig. 1C, D). The same sensor array has been used for all experiments. The data monitoring and storage was carried on by a AE data digitization system from ITASCA-Image, with the acquisition occurring at a sampling frequency of $10 \mathrm{MHz}$ in triggered mode, i.e. AE waveforms were stored once a set of parameters is satisfied (Fazio 2017; Fazio et al. 2017). The AE data acquisition spanned the entire hydraulic fracturing process, from the start of fluid injection to the commencement of fluid depressurization once the hydraulic fracture or pressure equilibration has been achieved, with data processing performed after the conclusion of the experiments.

The experimental procedure consisted of three stages: hydrostatic compaction, triaxial compaction and fluid injection (Fig. 2) (Gehne and Benson 2019). During the hydrostatic compaction, confining and axial stress were increased simultaneously to reach the chosen conditions. This was 


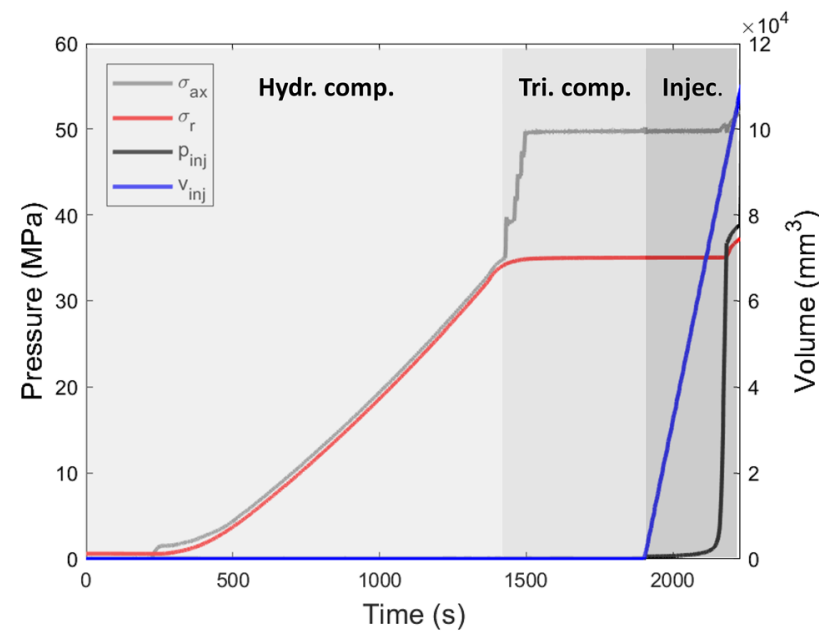

Fig. 2 Temporal variation of pressure and injected volume for a three-stage-experiments: hydrostatic compaction (light grey) with simultaneous increase in confining $\left(\sigma_{\mathrm{r})}\right.$ and axial $\left(\sigma_{\mathrm{ax}}\right)$ stress; triaxial compaction (middle grey) with only $\sigma_{\mathrm{ax}}$ being increased; injection (dark grey) with initiation of injected volume $\left(v_{\text {inj }}\right)$ and, consequently, injection pressure $\left(p_{\text {inj }}\right)$

followed by the triaxial compaction stage where only axial stress was increased. As described by Gehne and Benson (2019), this step was required to prevent the back-pressure of the injection fluid to lift the axial piston when the injection pressure exceeded the confining stress. Once a stable condition has been reached, both confining and axial stress were kept constant via the servo-controlled pumps and fluid was injected into the borehole through the open-end packer to stimulate nucleation and propagation of a hydraulic fracture system, marking the end of the experiment. During the hydraulic injection phase axial stress was still servo-controlled to remain higher than both confining and injection pressure (Gehne et al. 2020).

When permeation is sufficiently high to prevent the pressurization of the borehole and the injection fluid reached the interface between rock and rubber jacket, the injection pressure then equilibrates with the confining stress, also signifying the end of the experiment. All experimental stages were run at room temperature $\left(23{ }^{\circ} \mathrm{C}<T<25{ }^{\circ} \mathrm{C}\right)$. Post-test examination included photos of the tested samples, as well as thin sections cut perpendicular to the fracture plane. Finally, mechanical and $\mathrm{AE}$ data are processed and compared together to elucidate the fracturing/permeation process. In particular, AE events are located through the simplex algorithm (Fazio 2017; Nelder and Mead 1965), while the source mechanism is approximated using the polarities of the P-wave first arrival, defined as:

$\mathrm{pol}=\frac{1}{k} \sum_{i=1}^{k} \operatorname{sign}\left(A_{i}\right)$

where $A$ is the arrival recorded at the $i$ sensor, and $k$ is the number of sensors (Stoeckhert et al. 2015; Zang et al. 1998).

\section{Results}

A series of experiments was conducted on both BS (four samples) and COS (two samples) as shown in Table 1, conducted at room temperature and in dry conditions. Specimens of BS used JULABO Thermal Bath Fluid based on silicone (kinematic viscosity at $20^{\circ} \mathrm{C}: 55 \mathrm{~mm}^{2} / \mathrm{s}$ ) as the injection fluid due to the high permeability of the rock to prevent excessive permeation. The flow rate was $10 \mathrm{~cm}^{3} /$ min in BS4 and BS5 experiments and $20 \mathrm{~cm}^{3} / \mathrm{min}$ in BS7 and BS8 experiments. In addition, to aid hydraulic fracturing, an inner sleeve was present in BS4 and BS8 samples. Pressure conditions were kept constant for all BS experiments, with axial stress $\left(\sigma_{\mathrm{ax}}\right)=50 \mathrm{MPa}$ and confining pressure $\left(\sigma_{\mathrm{r}}\right)=35 \mathrm{MPa}$. Specimens of COS were injected with water (with a lower viscosity than oil) as permeation is less of a challenge due to low permeability of the rock. Two experiments using specimens COS 1 and $\operatorname{COS} 2$ were performed at different flow rates of $10 \mathrm{~cm}^{3} / \mathrm{min}$ and $20 \mathrm{~cm}^{3} /$ min, respectively, and with $\sigma_{\mathrm{ax}}$ of $80 \mathrm{MPa}$ and $60 \mathrm{MPa}$, respectively. In both experiments $\sigma_{\mathrm{r}}=35 \mathrm{MPa}$. In COS1 $\sigma_{\mathrm{ax}}$ was set to $60 \mathrm{MPa}$, and increased to $80 \mathrm{MPa}$ to keep $\sigma_{\mathrm{ax}}>P_{\mathrm{b}}$. Both samples experienced hydraulic fracturing.

Table 1 Physical properties and experimental conditions of the HF experiments

\begin{tabular}{llllllllcc}
\hline Test \# & Length $(\mathrm{mm})$ & Diameter $(\mathrm{mm})$ & $\sigma_{\mathrm{ax}}(\mathrm{MPa})$ & $\sigma_{\mathrm{r}}(\mathrm{MPa})$ & $\sigma_{\text {diff }}(\mathrm{MPa})$ & Fluid & $\begin{array}{l}\text { Flow rate } \\
\left(\mathrm{cm}^{3} / \mathrm{min}\right)\end{array}$ & Inner sleeve? & $P_{\mathrm{b}}(\mathrm{MPa})$ \\
\hline BS4 & 92.34 & 40.11 & 50 & 35 & 15 & Oil & 10 & Yes & 47.1 \\
BS5 & 92.15 & 40.10 & 50 & 35 & 15 & Oil & 10 & No & No \\
BS7 & 94.54 & 40.10 & 50 & 35 & 15 & Oil & 20 & No & No \\
BS8 & 90.71 & 40.12 & 50 & 35 & 15 & Oil & 20 & Yes & 45.6 \\
COS1 & 90.87 & 40.25 & 80 & 35 & 45 & Water & 10 & No & 67 \\
COS2 & 90.24 & 40.06 & 60 & 35 & 25 & Water & 20 & No & 52 \\
\hline
\end{tabular}




\subsection{Mechanical and AE Results with Bentheim Sandstone}

Observing the mechanical data of the BS experiments (Fig. 3A), two behaviors become evident: without the inner sleeve (fluid fracturing, FF, blue lines) the injection pressure first increases then plateaus at approximately $35 \mathrm{MPa}$, which is the same pressure as $\sigma_{\mathrm{r}}$; with the inner sleeve applied (sleeve fracturing, SF, black lines) the injection pressure increases non-linearly until $22 \mathrm{MPa}$, while after this point the increase steepens up to 45-47 MPa, when a pressure drop of around 8-10 MPa is observed. After this first stress drop, a second stress decrease occurs once the injection pressure $\left(p_{\text {inj }}\right)$ recovered slightly. Using post-test analysis, the pressure drops are associated to the formation of fractures parallel to $\sigma_{\mathrm{ax}}$, visible in both experiments (Fig. 3B, circled in red BS8 and BS4). Instead, in BS5 and BS7 no pressure drop is observed and both samples remain intact after the experiments (Fig. 3B, samples in the middle).
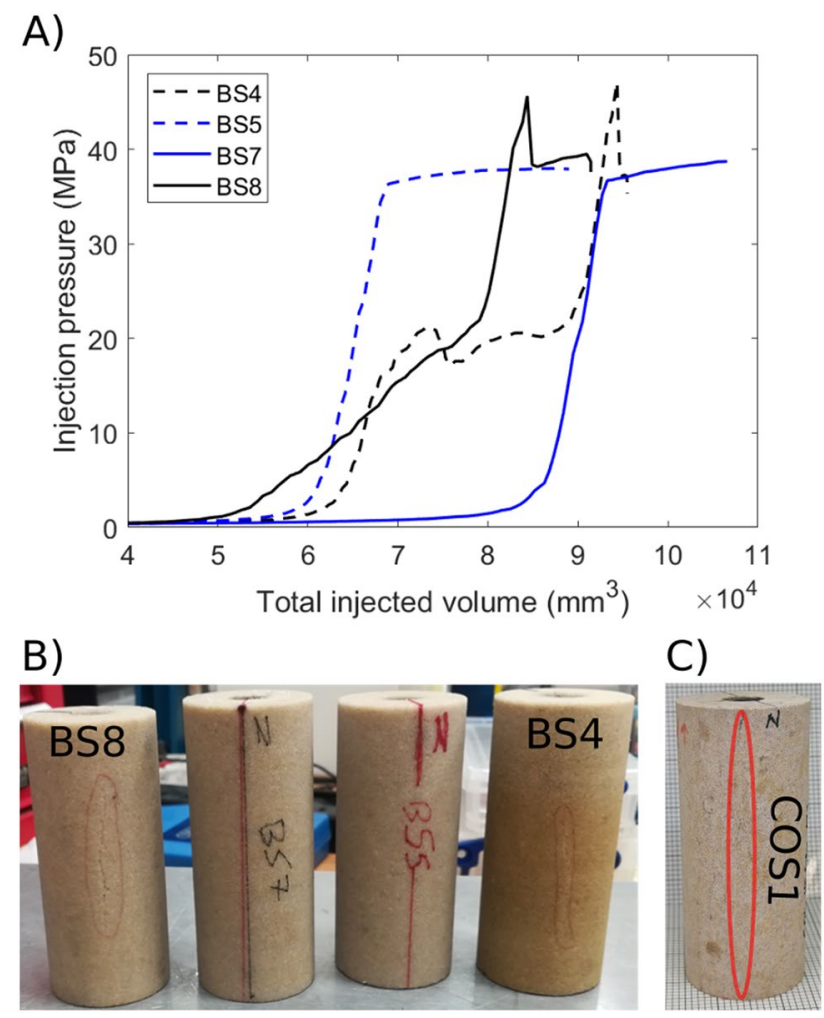

Fig. 3 A injection pressure vs total injected volume for all BS experiments, plotted until the end of the injection phase. While BS5 and BS7 (blue lines) show a plateau of injection pressure around $35 \mathrm{MPa}$, in BS4 and BS8 (black lines) injection pressure increases up to $47 \mathrm{MPa}$ before instantaneously dropping by $10 \mathrm{MPa}$. B Samples after completion of the experiments. Samples BS5 and BS7 (in the centre), having no inner sleeve, remained intact. BS4 and BS8, hosting an inner sleeve, show fractures (circled in red) parallel to the direction of $\sigma_{\mathrm{ax}}$. $\mathbf{C}$ Core of COS1 after the fracturing experiment, with a fracture spanning the entire length of the sample, circled in red (color figure online)
Combining $\mathrm{AE}$ and mechanical data, it is possible to appreciate the effect of presence of the inner sleeve on sample behavior upon fluid injection and pressurization. Figures 4 and 5 show BS7 (FF) and BS8 (SF), respectively, both with fluid injected at $20 \mathrm{~cm}^{3} / \mathrm{min}$. Only the successfully located events are plotted in these figures and considered for further considerations. As shown in Table 2, the majority of these events were located during the experiments that reached failure. However, regardless of number of located events, the average location error remains below $2 \mathrm{~mm}$ in all four experiments, with a maximum error of $5.67 \mathrm{~mm}$ (in BS4).

In BS7, as the fluid is injected at constant rate, $p_{\text {inj }}$ slowly increases up to about $0.8 \mathrm{MPa}$ (high-speed data are missing at the beginning of the injection, but $p_{\text {inj }}$ did not increase during the missing period, as shown in Fig. 2), then shows a faster increasing rate up to a pressure of $35 \mathrm{MPa}$, concurrent with a sharp decrease of volumetric strain, implying that the sample experiences extension. At this point, $p_{\text {inj }}$ plateaus, marking a hydraulic event for this experiment. AEs were recorded during the pressurization phase but no further events are observed once the injection pressure reaches $35 \mathrm{MPa}$ (Fig. 4A). Mechanical data reveal neither axial nor radial strain prior to the hydraulic event, with hardly more than one AE per second, while afterwards, radial strain data show a quasi-simultaneous sample extension in both directions. In the meantime, axial strain remains unchanged throughout the injection phase (Fig. 4B).

In $\mathrm{BS} 8, p_{\text {inj }}$ grows at constant rate until approximately $15 \mathrm{MPa}$. At this point, the pressure increase slows down, but once it overcomes $20 \mathrm{MPa}, p_{\text {inj }}$ increases even faster (compared to the first injection pressure increase) reaching a breakdown pressure $\left(P_{\mathrm{b}}\right.$, the hydraulic event in this experiment) of $45 \mathrm{MPa}$. The injection pressure then drops suddenly to $38 \mathrm{MPa}$, concurrently with a decrease in volumetric strain, but recovers back to $39.5 \mathrm{MPa}$ during the following $18 \mathrm{~s}$. During this time window a second, less steep, volumetric strain decrease is observed, unrelated to any injection pressure drop. After that a second pressure drop occurs together with a third steeper decrease in volumetric strain. AE events are recorded throughout the injection phase, showing an activity peak at $P_{\mathrm{b}}$ (Fig. 5A). Strain data are also different from the FF case. In fact, sample extension is temporally only observed in one direction (i.e. NS), through two different strain changes, related to the first two volumetric strain variations. Strain data in the opposite direction show no variation until several seconds later, when extension is recorded concurrently with the second pressure drop. It is likely that the fracture generated during the first pressure drop fully propagated to the edge of the sample during the second pressure drop, with the injection fluid flowing through it and pushing homogeneously against the rubber jacket. This is supported by 


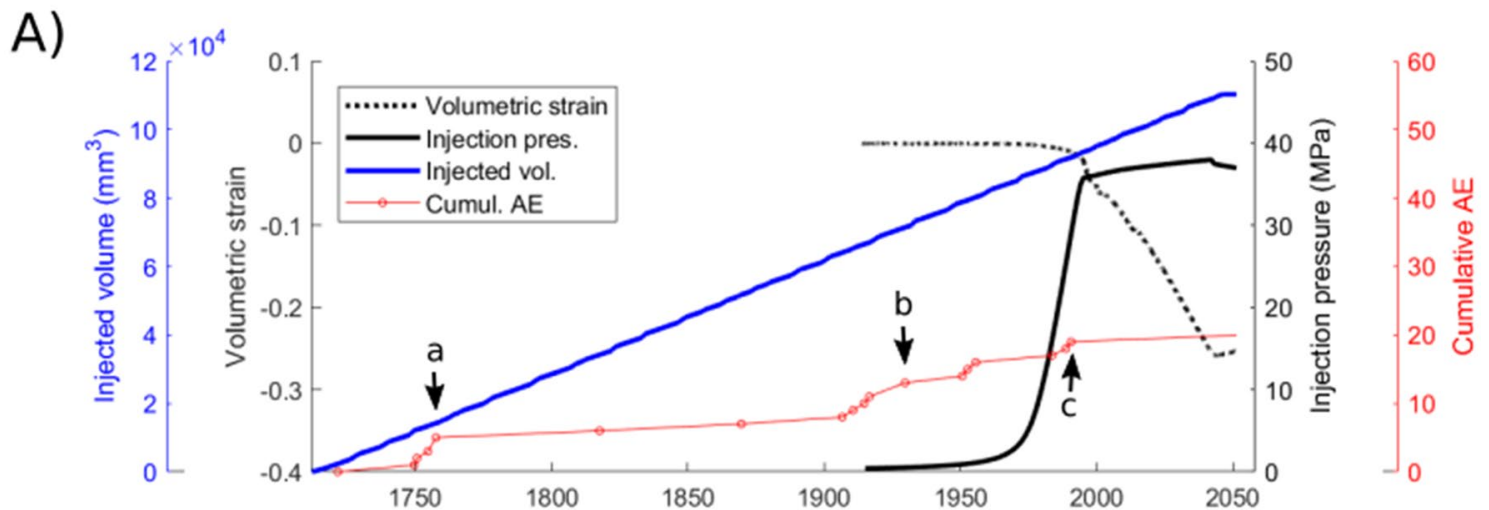

B)

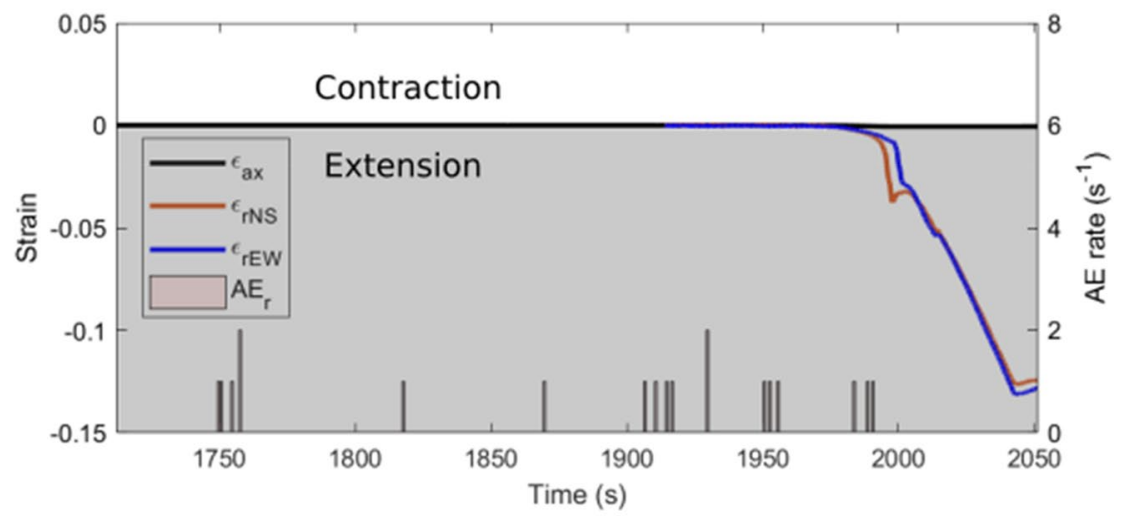

Fig. 4 A Injection pressure (solid black line) and injected volume (solid blue line) plotted together with cumulative AEs (red dots and line) and volumetric strain (dotted black line) for sample BS7. The

the injection pressure equaling the confining pressure and by the strain response, which remains constant after the second pressure drop.

AEs prior to fracturing, are isolated, with rarely more than one event/s, but at the time of $P_{\mathrm{b}}$, AEs form a cluster with an activity rate of six events/s, followed by a further cluster of up to five events/s at the time of the second stress drop (Fig. 5B). To better understand the fast-changing conditions at $P_{\mathrm{b}}$, a $60 \mathrm{~s}$ zoom-in of both Fig. $5 \mathrm{~A}$ and $\mathrm{B}$ is presented in Fig. 5C and D, respectively. After a hiatus of $30 \mathrm{~s}$, AE activity recommences just before $P_{\mathrm{b}}$, continuing with a higher AE rate during and immediately after the hydraulic event. This is followed by a relatively quiet 15 -s-long period (only one event is recorded) and a second burst of activity at $t=2030 \mathrm{~s}$ (Fig. 5C and D). The zoom-in of the strain data (Fig. 5D) reveals how the radial strain shows sample extension along the NS direction simultaneously with $P_{\mathrm{b}}$. Instead, extension along the EW direction occurs $18 \mathrm{~s}$ later after $P_{\mathrm{b}}$, thus representing the time required for the generated fracture to reach the edge of the sample. Considering that the thickness of the hollow cylinder is $13.6 \mathrm{~mm}$, the fracture propagates at $0.76 \mathrm{~mm} / \mathrm{s}$. lower-case letters indicate the time of the snapshots shown in Fig. 6. B Axial, NS and EW radial strain plotted together with AE rate (color figure online)

At the time of both pressure drops, at least $2 \mathrm{AE}$ events were recorded in a time span of $5 \mathrm{~s}$, totaling 19 AEs during the first pressure drop and 16 AEs during the second one.

Figure 6 shows the temporal and spatial evolution of the AEs in BS7 represented as three snapshots taken at different time during the injection stage (see small letters and arrows in Fig. 4A), before the injection pressure plateaus at $35 \mathrm{MPa}$ (no further events are recorded after that). At the early stage of injection, at ca. $t=1750 \mathrm{~s}$, a first burst of five events occurs (Fig. 6a). These are predominantly T-type (80\%) with three of these around the borehole on the upper face of the sample, while the forth located at half-length near the northern edge. The small-magnitude, S-type event instead appear on the lower face. Before the build-up of the injection pressure, further eight events are recorded over a time span of $175 \mathrm{~s}$ (Fig. 6b). These are equally distributed between the upper face near the borehole, the lower face and in the lower half near the half-length, without showing any preferential orientation. The majority (62\%) are T-type, while one and two events are, respectively, C- and S-type. During the build-up of injection pressure, six additional events are recorded in ca. 40 s (Fig. 6c). Apart from one S-type, all other events 
are T-type, mostly occurring either on the upper face or in the lower half of the sample.

Figure 7 shows the temporal and spatial evolution of the AEs in BS8, before hydraulic fracturing (see Fig. 5A). During the early stage of fluid injection four AEs are recorded (Fig. 7a). These are mostly T-type, forming NW-SE alignment, although equally distributed between the upper and lower face of the sample. During the beginning of pressurization, 3 T-type events occurs within $50 \mathrm{~s}$ (Fig. 7b). As before they appear at both sample's faces and along a NW-SE direction. A small burst of three events (Fig. 7c) appears at $t=1975 \mathrm{~s}$, when the increase of pressure slows down, before a hiatus in AE activity of ca. $30 \mathrm{~s}$. All sources are represented with the T- and C-type oriented NE-SW, although occurring in opposite sides of the pressurized sealed chamber (in yellow).

Figure 8 shows the temporal and spatial evolution of the AEs in BS8, just preceding and during hydraulic fracturing (see Fig. 5C). The first burst of events (20 AEs in 7 s, Fig. 8d) is associated with the initiation of hydraulic fracturing (the first pressure drop and volumetric strain). These are mostly S-type occurring along the NE-SW direction (the vast majority in SW quadrant) and at half-length of the sample, where the pressurized sealed chamber, in yellow, is located. Further five events are recorded between the two stress drops (Fig. 8e). During this time span (17 s) a variation of volumetric strain also occurs, associated with a high-magnitude, T-type event near the SW margin of the borehole. The other four events also occur in SW quadrant, with $1 \mathrm{C}$-type showing large relative magnitude, with an upward migration of the locations. No AEs are recorded in the lower half of the sample. After the second and last pressure drop, $14 \mathrm{AE}$ are recorded (Fig. 8f). The upward migration of locations continues reaching the sample edge at the upper face, although some AEs also appear in the lower half of the sample. T-type activity resumes in this phase, while being almost absent in the previous snapshot. Three AEs also appear in the NE quadrant.

The fracture wing in the SW quadrant of the sample, which appears to be non-planar, is clearly visible once the sample has been dissected in half (Fig. 9). In contrast, the fracture wing in the NE quadrant is less obvious and a small trace is visible about half-distance between the borehole and the edge of the sample.

Figure 10 shows an evolution of the source type of the events and the difference between FF and SF experiments in the highly porous BS material. In BS7, the vast majority (75\%) are T-type sources, coherent with a general expansion behavior of the sample in FF mode, when the injection fluid saturates and expands homogeneously the high amount of pore space. The behavior in BS8 is different when compared the pre- and post-hydraulic event. Before fracture the majority of AE sources are still T-type (67\%), but both C- and
S-type sources are increasing when compared to BS7. This can be linked to the sealed and preferentially orientated pressurization, with the appearance of larger number of Cand S-type sources. After the generation of the hydraulic fracture, the number of S-type sources almost triple (68\%), together with a further increase in C-type (increase to 23\%) and a decrease in T-type sources to just 19\%. This suggests that, once the fracture is formed, shear type mechanisms (rather than tension) modes best characterize the post-fracturing process with contraction occurring in response to opening of the fracture.

\subsection{Mechanical and AE Results in Crab Orchard Sandstone}

Figure 11 shows that the injection pressure increases up to $30 \mathrm{MPa}$ (from $t=1895 \mathrm{~s}$ to $t=1925 \mathrm{~s}$ ), then decelerates, reaching $35 \mathrm{MPa}$. This is followed by another increase in pressure at a slower, non-linear rate (when compared to the first injection pressure increase) reaching the $P_{\mathrm{b}}$ at $67 \mathrm{MPa}$ $(t=1971 \mathrm{~s})$. The injection pressure then drops to $35 \mathrm{MPa}$, concurrent with a drop in volumetric strain (Fig. 11A). After that the injection pressure remains quasi constant at $35 \mathrm{MPa}$, while volumetric strain experiences a second, slower decrease few seconds after the first drop.

Fewer AE events were located in COS experiments when compared to the BS ones with inners sleeve (i.e. BS4 and BS8, Table 2). In addition, locations in COS samples showed both higher average and maximum errors. AE activity is negligible throughout the injection phase, but shows an activity peak at $P_{\mathrm{b}}$ (Fig. 11A and B). These AE events form a cluster with six events/s at the time of $P_{\mathrm{b}}$. Sample extension is recorded along the $\mathrm{N}-\mathrm{S}$ direction from $t=1940 \mathrm{~s}$, ca. $30 \mathrm{~s}$ before $P_{\mathrm{b}}$, while extension along the E-W direction occurred later and is attributed, as per experiment BS8, to the injection fluid reaching the edge of the sample once the fracture fully propagated.

Expanded views (60 s) of Fig. 11A and B (represented as Fig. $11 \mathrm{C}$ and $\mathrm{D}$, respectively), give a more detailed representation of the events occurring around the $P_{\mathrm{b}}$. While the injection pressure takes $1 \mathrm{~s}$ to drop from 67 to $35 \mathrm{MPa}$, the decrease in volumetric strain is not linear and takes up to $9 \mathrm{~s}$ before stabilizing at -0.09 . However, after $9 \mathrm{~s}$ volumetric strain slowly decreases again, while the injection pressure remains constant (Fig. 11C).

AE activity recommences at high AE rate at the $P_{\mathrm{b}}$ time, after a hiatus of $30 \mathrm{~s}$. The AE rate remain high ( $>5$ events/s) only during the $2 \mathrm{~s}$ close to $P_{\mathrm{b}}$, while only three isolated events are recorded after that (Fig. 11D). The strain recordings (Fig. 11D) show an early radial extension along the $\mathrm{N}-\mathrm{S}$ direction as well as contraction along the vertical axis, the latter linked to the increase in axial pressure to avoid the back-pressure effect of the 
A)

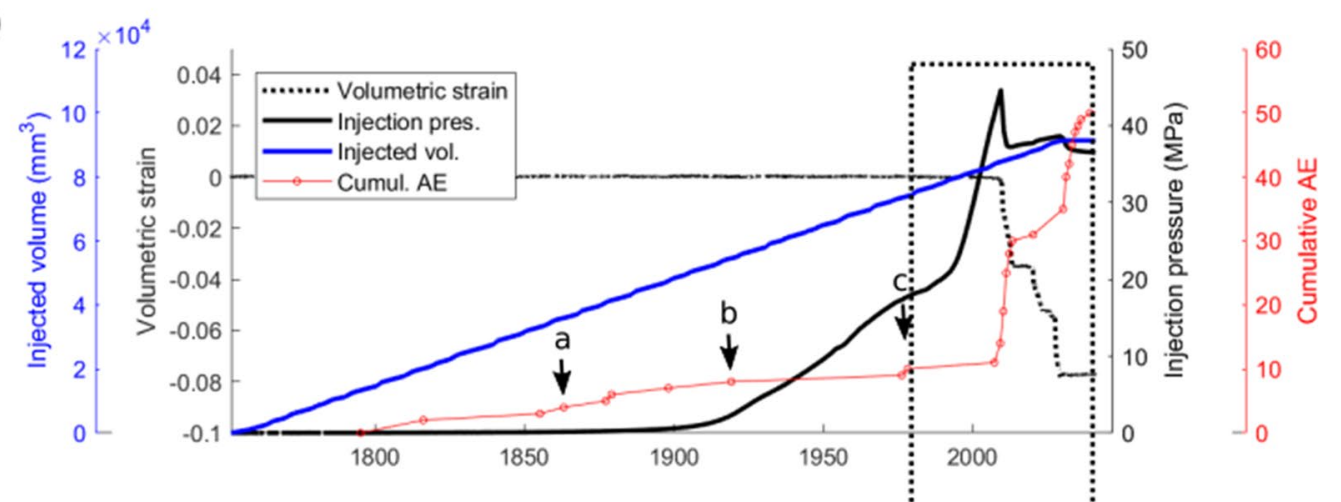

B)

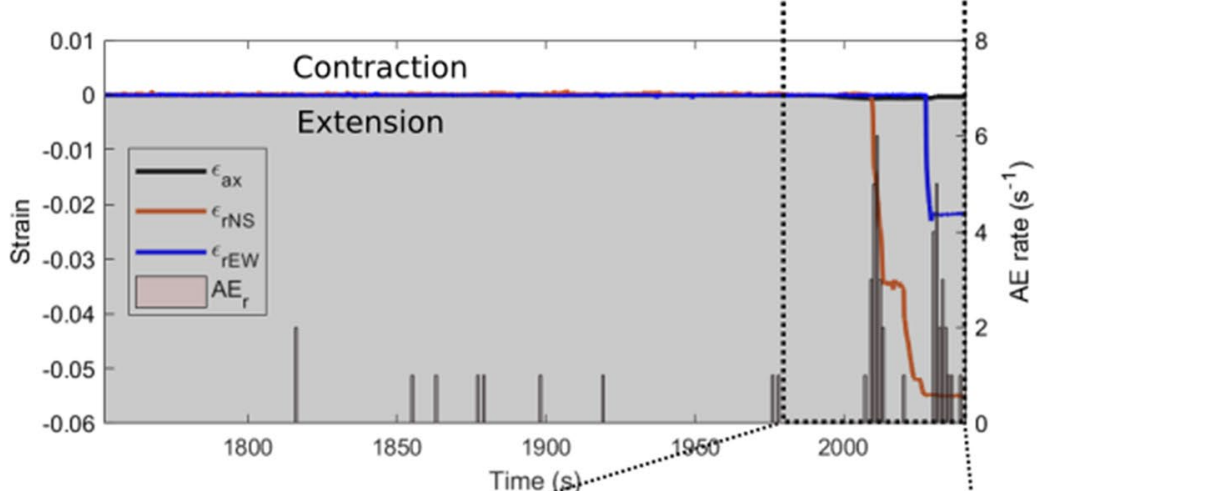

C)

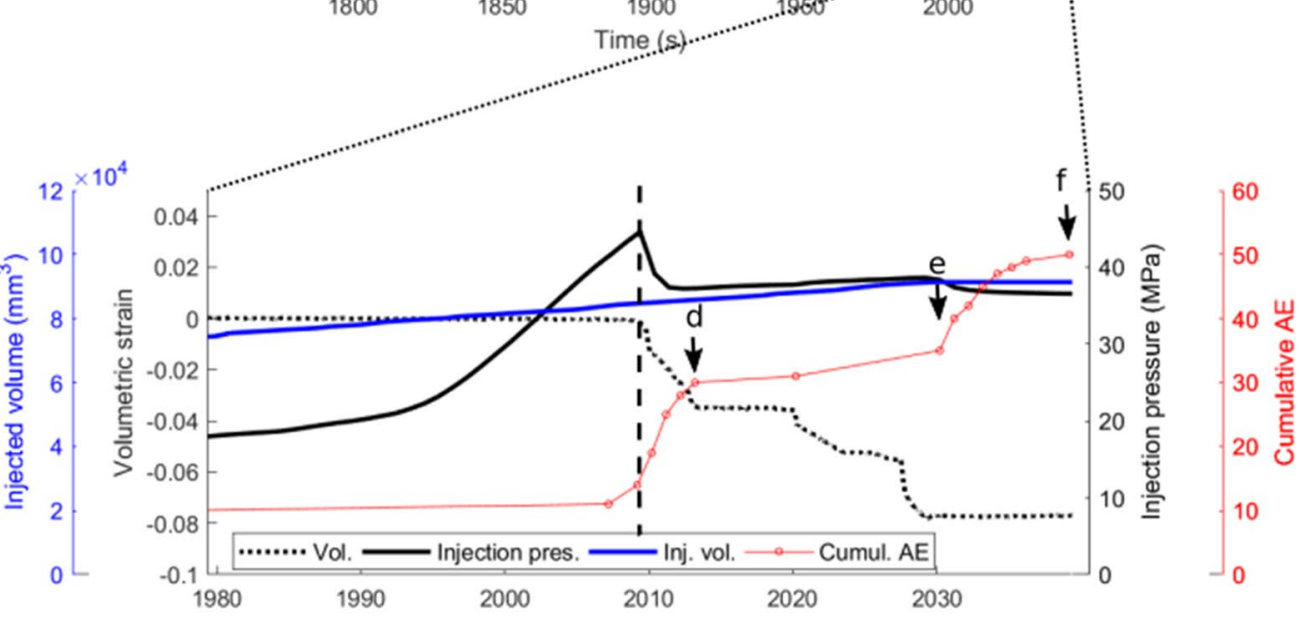

D)

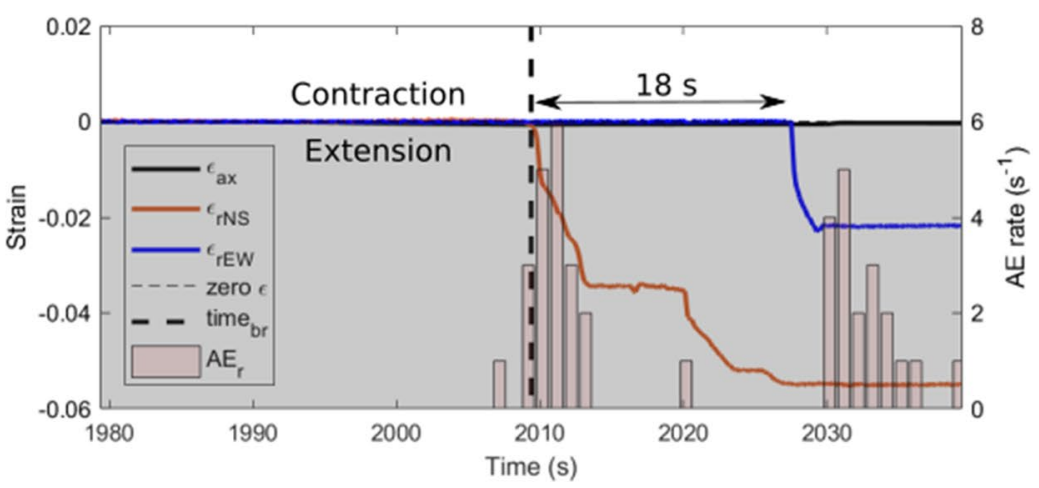


4Fig. 5 A Injection pressure (solid black line) and injected volume (solid blue line) plotted together with cumulative AEs (red dots and line) and volumetric strain (dotted black line) for sample BS8. The lower-case letters indicate the time of the snapshots shown in Fig. 7. B Axial, NS and EW radial strain plotted together with AE rate. C Sixty seconds zoom-in at $P_{\mathrm{b}}$ of plot A. The lower-case letters indicate the time of the snapshots shown in Fig. 8. D Sixty seconds zoom-in at $P_{\mathrm{b}}$ of plot B (color figure online)

injected fluid on the axial piston. At $P_{\mathrm{b}}, \mathrm{N}-\mathrm{S}$ radial strain drop suddenly, but shows a fluctuating, non-monotonic response until the end of the experiment. Extension along the E-W direction is observed at $t=1979 \mathrm{~s}\left(8 \mathrm{~s}\right.$ after $\left.P_{\mathrm{b}}\right)$, showing fluctuating, monotonic behavior. At $t=1975 \mathrm{~s}$, the strain in both directions decreases at the same rate.

As for BS8, using the lag time of sample extension between the two radial strain measurements, it is possible to calculate the fracture propagation speed. This corresponds to $1.7 \mathrm{~mm} / \mathrm{s}$.

Figure 12 shows the temporal and spatial evolution of the AEs in COS1, before and in the $2 \mathrm{~s}$ around $P_{\mathrm{b}}$ (see Fig. $11 \mathrm{~A}$ and $\mathrm{C}$ ). The only event recorded during the early stage of borehole pressurization is a T-type, located at the lower face of the sample (Fig. 12a). Prior to fracturing, six AEs are recorded, forming a non-axial NE-SW alignment in the east, upper half sector. All sources are represented here (Fig. 12b). Immediately after fracturing, five more AEs, with S- and T-type sources, appear in the lower half of the sample and oriented NW-SE.

Figure 13 shows the last three isolated events, all S-type and located in the east sector, occurring when injection pressure stabilizes at $35 \mathrm{MPa}$ (see Fig. 11C). The first $\mathrm{AE}$ recorded during this stage continues the migration of the non-axial NW-SE alignment in the lower half of the sample (Fig. 13d), while the following event (high relative magnitude) appears at half-length within the NE-SE alignment (Fig. 13e), concurrent with a fluctuation of the $\mathrm{N}-\mathrm{S}$ radial strain. The last event is located at the eastern edge on the upper face, along the non-axial NW-SE trend (Fig. 13f). Only the NE-SW fracture wing, imaged by AEs, is visible in the post-test dissected sample (Fig. 3C).

Concerning the source type of the AE events, Fig. 14 reveals the source type of a low porosity and low-permeability rock material after fracture development, since only one event is recorded before fracturing (which has C-type source). S-type sources dominate this phase (62\%), followed by T-type (19\%) and C-type (29\%) ones. This indicates that, once the fracture is formed in the rock material, shearing (not tension) modes best characterize the post-fracturing period. Although with fewer AE recorded, this is similar to the post-breakdown phase observed in BS8.

\section{Discussion}

\subsection{Effect of Wall Permeability on Breakdown Pressure (BS only)}

Although it was impossible to assess whether the silicone rubber was distributed homogeneously on the inside of the borehole wall, the resultant inner sleeve has demonstrated to be efficient in making the borehole less permeable and prevented infiltration of the injected fluid into the highly permeable rock matrix. Before fracturing, the SF and FF experiments on Bentheim Sandstone can be considered as examples of hydraulic fracturing with, respectively, lowly permeable and highly permeable borehole on the same rock, so without changing the mechanical and physical properties of the surrounding rock matrix. Previous studies (Brenne et al. 2013; Song et al. 2001; Stoeckhert et al. 2014, 2016) show that $P_{\mathrm{b}}$ increases significantly in $\mathrm{SF}$ tests compared to FF tests run on the same material, from twice up to approximately six times the value in FF. When applying different equations to model and calculate $P_{\mathrm{b}}$ (Table 3), the SF-based equations using our laboratory data tend to overestimate $P_{\mathrm{b}}$. A similar result, although with lower values, is obtained using the linear elastic equations (both with and without considering the ratio between inner and outer diameter of the hollow cylinder). Instead, an accurate estimate is given by the linear elastic approach with poroelastic effects (45.2-48.3 MPa), implying that hydraulic fracturing is achieved without a multiple increase in $P_{\mathrm{b}}$ and, consequently, lower stress drop and lower induced AE. In the field, this means a reduced seismic risk, which is of great importance in well-stimulation processes.

As fluid leak-off through the rock matrix is suggested by both initial low-pressurization rate and $\mathrm{AE}$ events, the poroelastic approach is the most suitable to explain such a low value for breakdown pressure, even if the experiment was conducted in SF mode. A relative low breakdown pressure could be associated with large borehole diameter and low injection rate (Brenne et al. 2013; Ito and Hayashi 1991; Zhuang et al. 2018). Regarding the influence of the magnitude of the injection rate, we experimented with 10 and $20 \mathrm{~mL} / \mathrm{min}$ in BS4 and BS8, respectively, with the effect that actually the higher breakdown pressure is found in BS4. However, due to a marginal difference between the observed values, we assumed that in our experiments the injection rate does not influence breakdown pressure. Regarding the borehole size effect, all of our experiments were conducted in hollowed cylinders of radius $20 \mathrm{~mm}$ with a central, axial borehole of radius $6.4 \mathrm{~mm}$. While we cannot draw any conclusion from our tests regarding the borehole effect, we noticed that in experiments with 
Table 2 Recorded AE events and location error of the HF experiments

\begin{tabular}{llcc}
\hline Test \# & $\begin{array}{l}\text { Located } \\
\text { events }(\#)\end{array}$ & $\begin{array}{l}\text { Average location's } \\
\text { error }(\mathrm{mm})\end{array}$ & $\begin{array}{l}\text { Maximum loca- } \\
\text { tion's error (mm) }\end{array}$ \\
\hline BS4 & 37 & 2.04 & 5.56 \\
BS5 & 27 & 1.30 & 3.10 \\
BS7 & 19 & 0.75 & 2.10 \\
BS8 & 49 & 1.48 & 3.48 \\
COS1 & 15 & 4.67 & 11.27 \\
COS2 & 18 & 10.86 & 25.21 \\
\hline
\end{tabular}

a similar geometry and size (cm-size cylindrical sample with axial borehole, Brenne et al. 2013), an increase in borehole radius from 2 to $3 \mathrm{~mm}$ has only a marginal effect on the breakdown pressure in porous rocks. In our study, instead, with a radius approximately double than the above-mentioned work, the breakdown pressure is about six times lower than expected value estimated for hydraulic fracturing in SF mode. Although more experiments are required to investigate in more detail the borehole size effect, this cannot explain such a particularly low breakdown pressure observed in our SF experiments.

The linear elastic approach with poroelastic effects equation could be used for the BS data in FF mode. However, as shown in this study, discrete fracturing did not occur due to the intense fluid permeation through the highly permeable rock matrix. As shown in Table 3, the application of the inner sleeve in the SF experiments did not complete seal the borehole, but instead reduced its permeability to such a level that hydro-fracturing could occur. This suggests that the hydraulic fracturing equations are only valid for wall permeability $\left(k_{\mathrm{w}}\right)$ at the interface between the injection fluid and the rock matrix is below a critical permeability $\left(k_{\mathrm{wc}}\right)$, so that Eq. 3 should be written as

$P_{\mathrm{b}}=\frac{3 S_{\mathrm{h}}-S_{\mathrm{H}}+\sigma_{\mathrm{T}}}{2-\alpha \frac{1-2 v}{1-\nu}}-P_{0}$ for $k_{\mathrm{w}}<k_{\mathrm{wc}}$.

Therefore, borehole wall permeability does not only determine whether hydraulic fracturing is successful or not, but also controls breakdown pressure at which fracturing eventually occurs.

\subsection{Effect of Permeability on AE Activity}

$\mathrm{AE}$ activity was monitored throughout the injection phase in all experiments, revealing important information on how the permeability of the rock affected the microseismicity. Whilst COS1 lacks precursory signals (aside from a single event), BS8 instead is characterized by 14 events before a burst of activity linked to $P_{\mathrm{b}}$. The majority of these events occurred early in the injection phase, while during the steepest increase of $p_{\text {inj }}$ preceding $P_{\mathrm{b}}$ only two events were recorded. During the early experimental stage the buildup of pressure is absent until 1900s and then only increases very modestly up to $t=1995 \mathrm{~s}$ (Fig. 5), which is due to partial leaking of the injected fluid through the semi-permeable inner sleeve. Similar behavior is observed during the whole injection phase in BS7 and during the second part of the of the injection phase in COS1, when also the increase of $p_{\text {inj }}$ slows down compared to its earlier stage. All these stages are characterized by the occurrence of mostly tensile AEs (see Fig. 10), suggesting that the events are caused by the leaking of pressurized fluids causing expansion of the pore space.

Conversely, during the stage of maximum pressure buildup (early on in COS1 and late in BS8), a paucity of AEs is apparent. Previous studies (Song et al. 2001; Zhuang et al. 2018) also linked the onset of AE activity with a change in rock permeability through the non-linear behavior of the pressurization rate, defining this point as the "apparent breakdown pressure". Therefore, we conclude that the rock matrix permeability has a major control in the generation of precursory AE activity during hydraulic fracturing processes, with the sources not necessarily linked to the formation of the eventual fracture zone, but to the escape of the injection fluid through the rock matrix and expansion of pore space. This is the case in experiment BS7, where, although no hydraulic fracturing occurred, the AE activity during the borehole pressurization stage is almost double than that observed in BS8 during the same stage. Applying this result to the field, an intense precursory seismic activity may be related to the permeation of fluid through the permeable rock matrix, rather than associated with rock fracturing.

\subsection{Fracture Propagation}

Two fluids of different viscosities are used (oil and water for BS and COS experiments, respectively) for the hydraulic fracturing processes described here. While the fracture geometry observed in COS1 (non-axial, single wing) is likely affected by a combination of both low fluid viscosity and high anisotropy inherent in the material (which promote cleavage-dominated fractures Ha et al. 2018; Meng and De Pater 2011; Stoeckhert et al. 2015)), the different fracture propagation speed between high permeable BS and low permeable COS samples is related to a combination of their different hydraulic conductivity and, once again, fluid viscosity.

To assess the fracture propagation time, we used the information given by the asynchronous extension shown by the radial strain data. In Sect. 3.1 and 3.2, we calculated a fracture propagation speed of 0.76 and $1.7 \mathrm{~mm} / \mathrm{s}$ for BS8 and COS1, respectively. In both BS and COS experiments, the radial extension at the $\mathrm{E}-\mathrm{W}$ direction is delayed when compared to the radial extension at the $\mathrm{N}-\mathrm{S}$ direction, with 
Fig. 6 Spatial and temporal evolution of cumulative AE activity represented in 3D and plan view at selected snapshots (see Fig. 4A) of experiment BS7. In (a) the first burst of five events is recorded in the early stage of fluid injection. In (b) additional eight events are shown, related to the long phase (175 s) before the injection pressure build-up. In (c) six AEs are recorded during the increase in injection pressure. The size of the symbols represents a normalized relative magnitude. The yellowcolored volume represents the pressurized sealed chamber a)
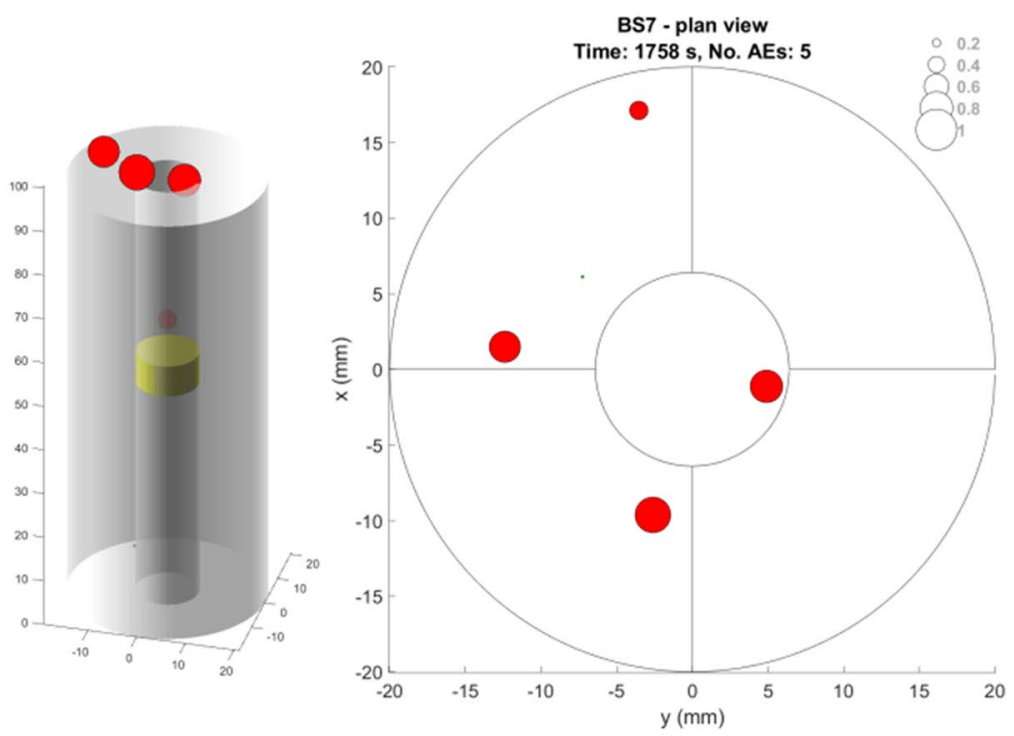

b)
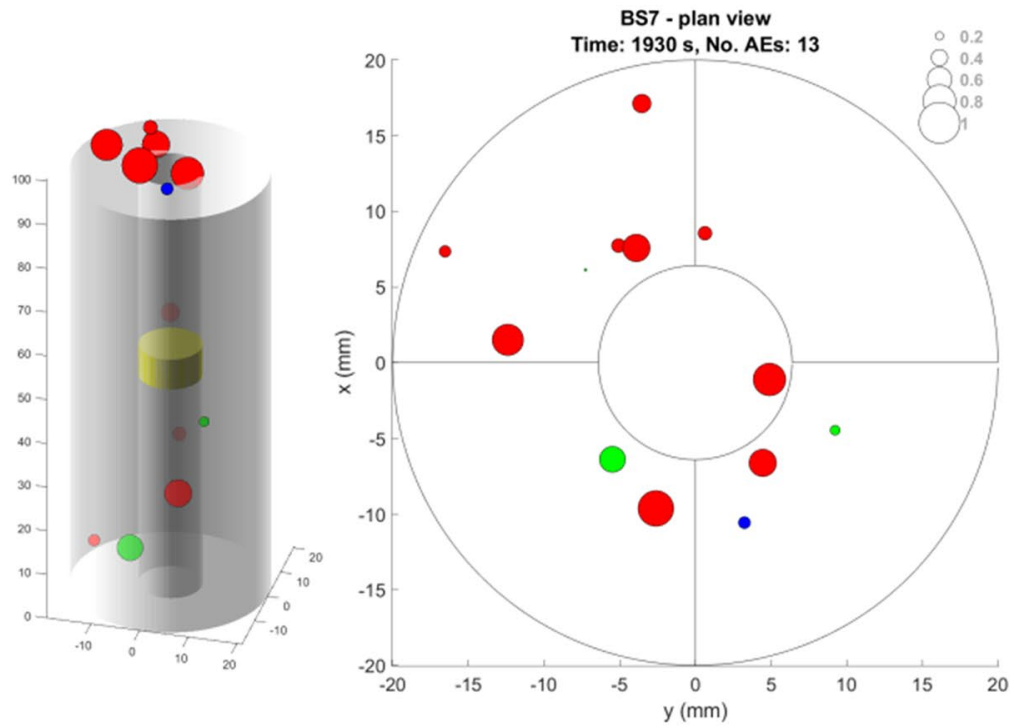

c)

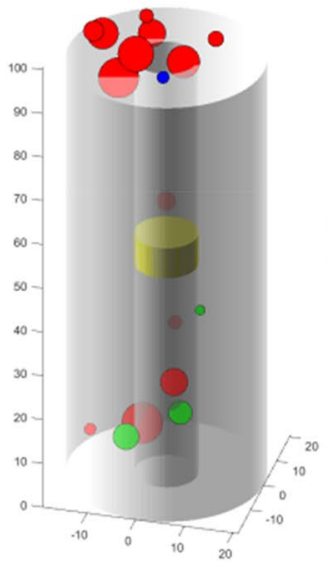

BS7 - plan view

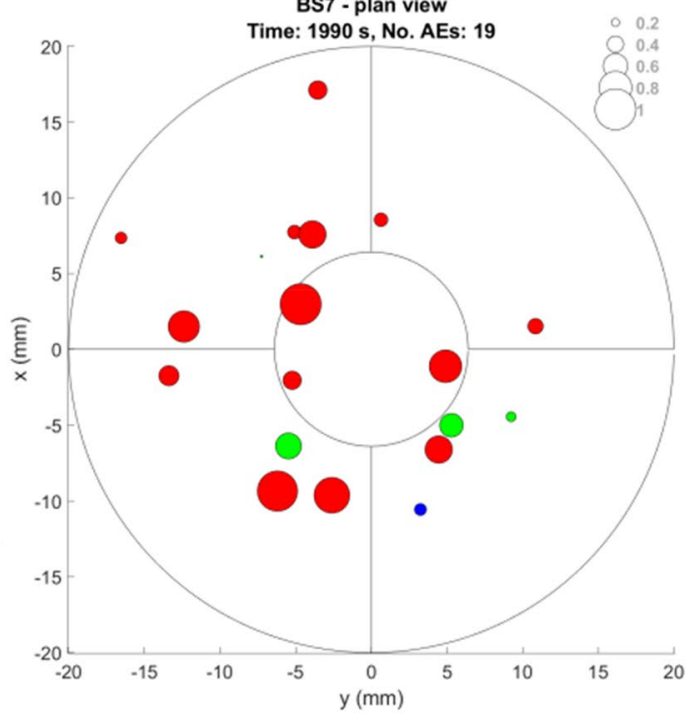


Fig. 7 Spatial and temporal evolution of cumulative AE activity represented in $3 \mathrm{D}$ and plan view at selected snapshots (see Fig. 5A) of experiment BS8, before hydraulic fracturing. In (a) four AEs are recorded during the early stage of fluid injection. In (b) three additional events occur during the beginning of pressurization. In (c) the last three AEs event before hydraulic fracturing are shown. The size of the symbols represents a normalized relative magnitude a)
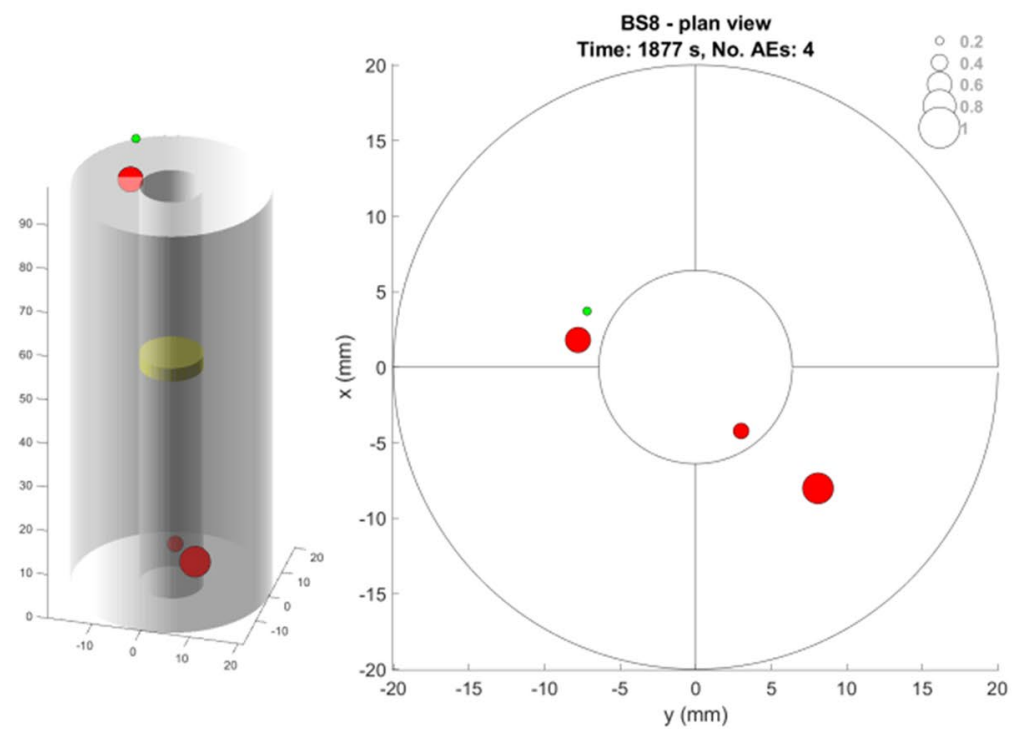

b)
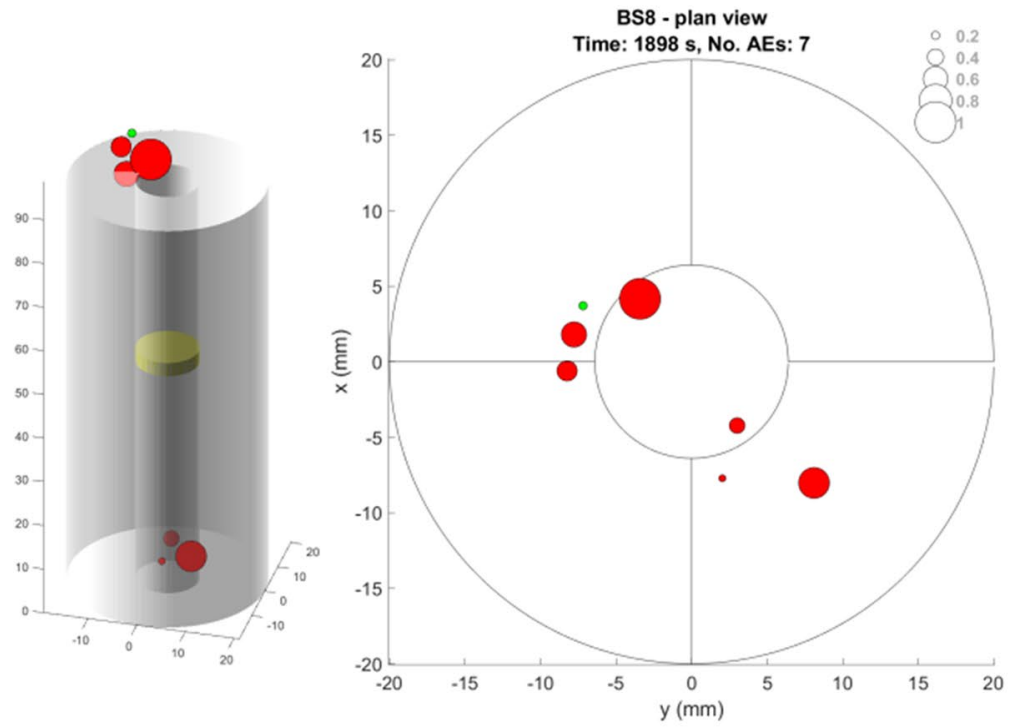

c)

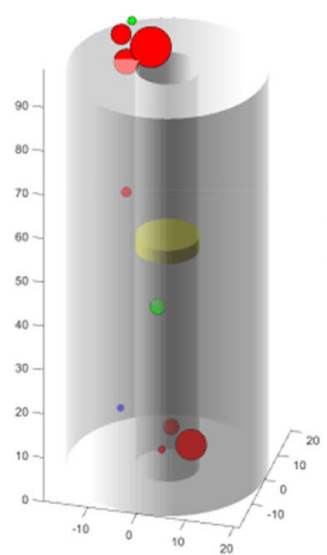


Fig. 8 Spatial and temporal evolution of cumulative AE activity represented in $3 \mathrm{D}$ and plan view at selected snapshots (see Fig. 5C) of experiment BS8, just preceding and during hydraulic fracturing. In (d) the first burst of events (20) associated to the initiation of hydraulic fracturing. In (e) five additional AEs are recorded between the two pressure drops. In (f) the events (14) occurring after the last pressure drop are shown. The size of the symbols represents a normalized relative magnitude d)
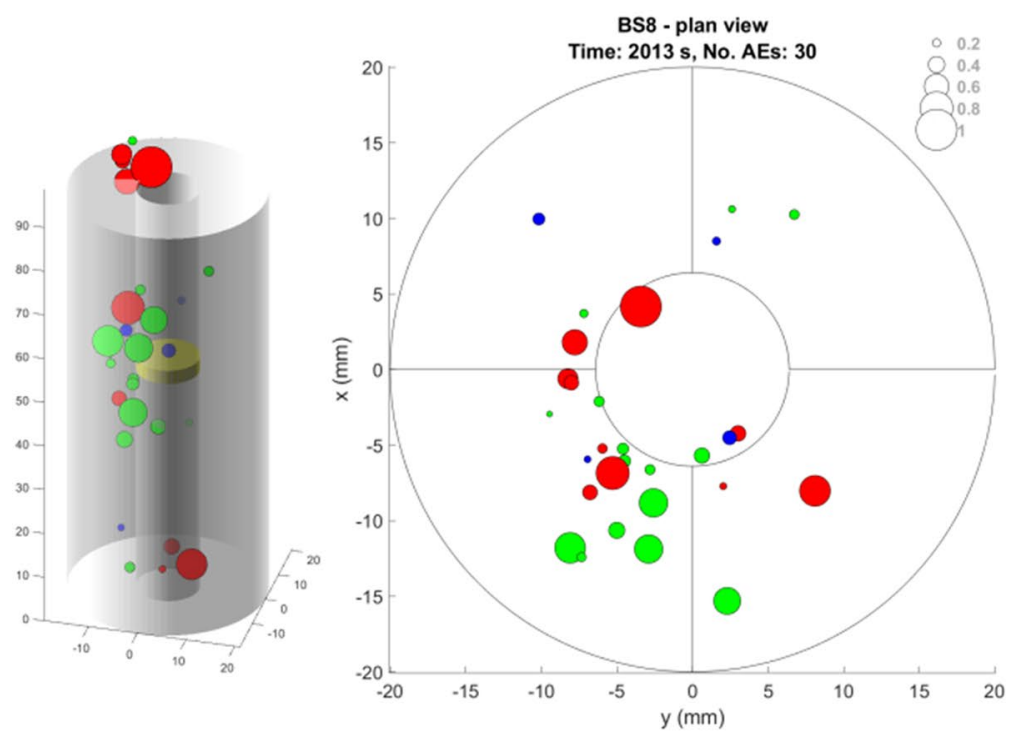

e)
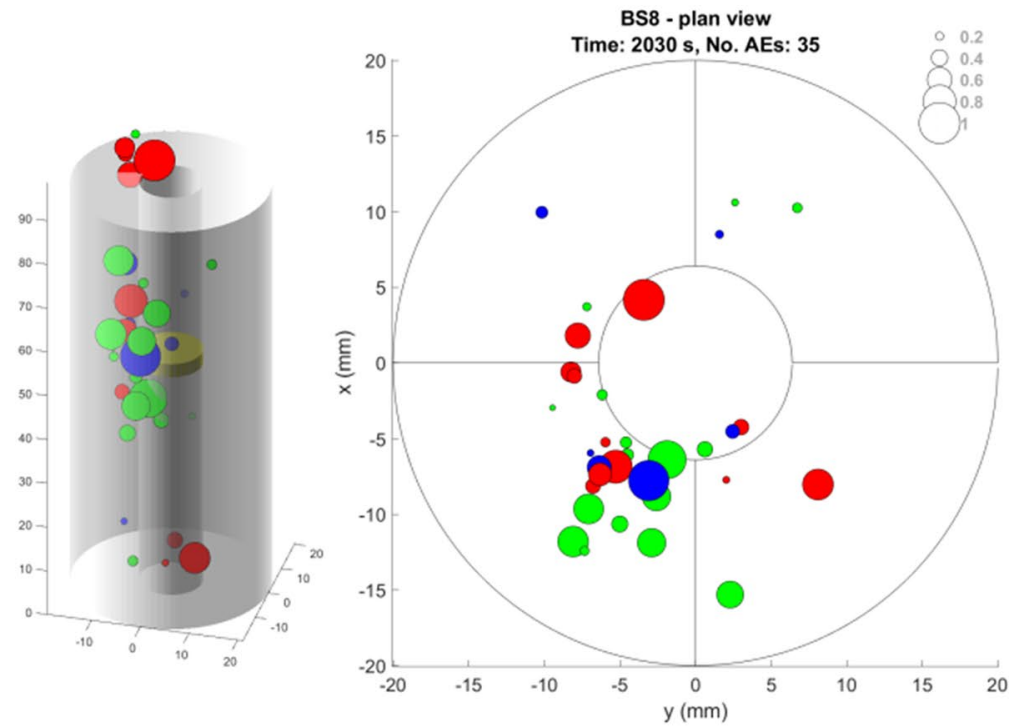

f)
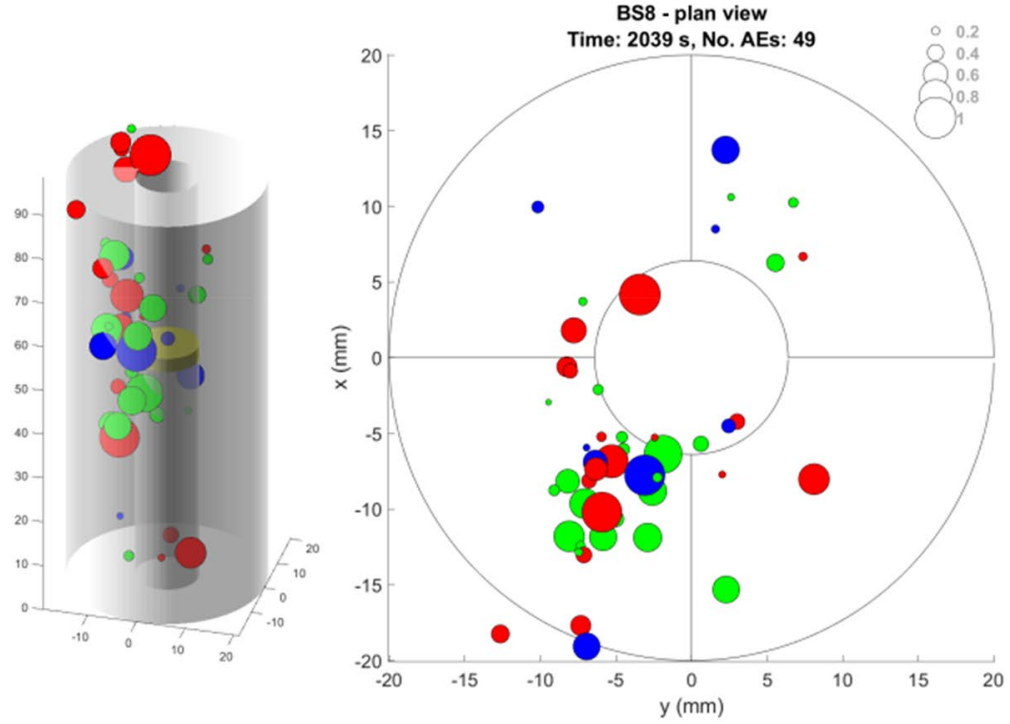


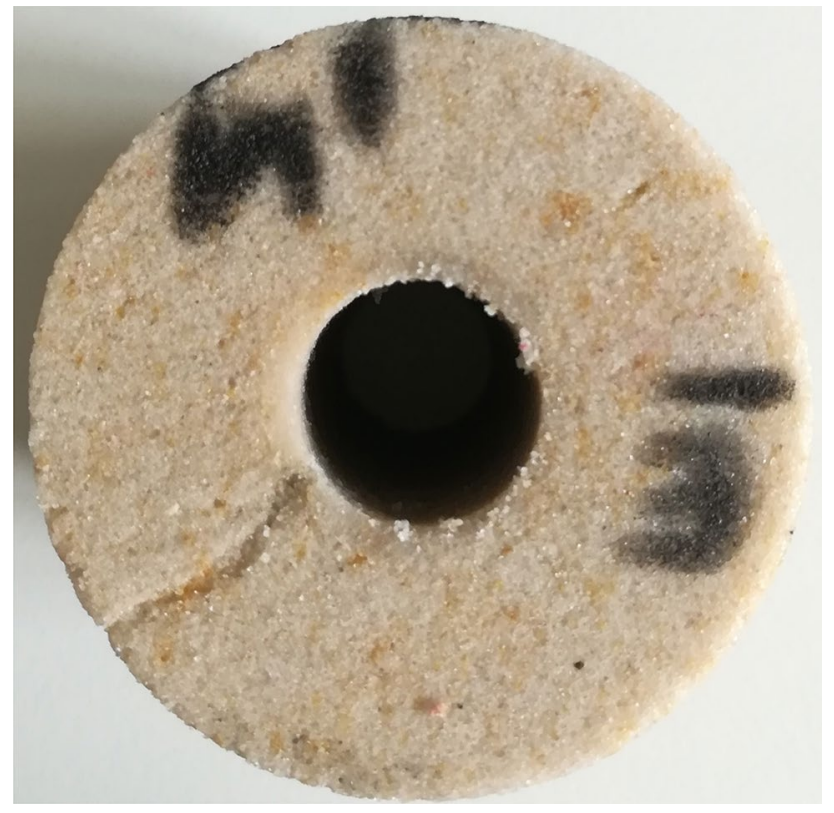

Fig. 9 View of BS8, cut at the middle point. A clear non-planar, arcuate fracture is present on the SW quadrant as well as a minor, barely visible fracture on the NE quadrant (visible around halfway between the borehole and the edge of the sample)

the latter occurring simultaneously with $P_{\mathrm{b}}$. This lag likely represents the time needed for the injection fluid to flow from the center of the sample to its edge through the fully developed fracture.

Figure 15 represents the distribution of the AE locations, parallel to the generated fracture, occurring at the time of sample breakdown. While AEs in BS8 reach the edge of the sample (i.e. the limits of the $y$ axis) $22 \mathrm{~s}$ after breakdown [we consider the location occurring at $22 \mathrm{~s}$ instead of that one occurring at $24 \mathrm{~s}$, because we include the average location error (see Table 2)], in COS1 AEs seem to reach the edge of the sample within the first second (when considering the three-times higher location error) (Fig. 15A). A 2.5 s zoomin (Fig. 15B) reveals a clearer picture of the first instants after breakdown. In particular it is apparent that six AEs in COS1 migrate quasi-monotonically towards one edge of the sample in $0.57 \mathrm{~s}$, at a speed of $23.9 \mathrm{~mm} / \mathrm{s}$. In BS8 instead, only the first two events show a clear migration to the edge of the sample, which could have been reached $0.29 \mathrm{~s}$ after breakdown, at a speed of $46.9 \mathrm{~mm} / \mathrm{s}$.

While this initial propagation speeds are coherent with a previous study showing that the propagation speed is higher for low viscous fluid and it is not affected by the type of material (Stanchits et al. 2015), the propagation speed calculated through the lag time of radial extension shows the opposite. We believe that at the initial stage of fracture propagation, fluid viscosity controls the propagation speed. Therefore, with high viscous oil (BS8), the fracture propagates faster compared to the case with low viscous water (COS). However, as the fracture propagates further in the highly permeable rock matrix of BS, the fluid leak-off increases as well.

Stanchits et al. (2015) compared Niobrara shale and Colton Sandstone, both having a similar and low-permeability $\left(10^{-18} \mathrm{~m}^{2}\right.$ (Yao et al. 2017) and $10^{-17} \mathrm{~m}^{2}$ (Stanchits et al. 2014), respectively) whilst Bentheim Sandstone has a permeability of up to $10^{6}$ times higher than Crab Orchard Sandstone. Consequently, it is likely that the injection fluid in BS experiments leaks off orthogonal to the walls of the induced fracture through the adjacent permeable rock matrix, with the consequence of requiring more fluids to build sufficient pressure to overcome fracture toughness, and ultimately slowing down fracture propagation. We believe that particularly high permeability, such as that of BS, does have such an impact on the fracture propagation so that fluid viscosity has negligible effect on this.

Fluid leak-off in BS8 causes pressure decrease at the tip of the fracture, likely to be responsible of the observed episodic fracture propagation pattern, visible in the oscillations of injection pressure and by the multiple drops in radial and volumetric strain (S. Gehne et al. 2019, 2020). On the other hand, in COS1, once the fracture reaches the edge of the sample, we observed a non-monotonic behavior of the radial strain, showing relative contraction on NS radial strain, where the nucleation of the fracture was recorded. Together with the locations of the AE, we believe that the initial fracture oriented NE-SW experienced fracture closure as a result of the opening of a quasi-perpendicular fracture headed ESE. A similar pattern of non-monotonic behavior of the radial strain associated with opening and closure of the fracture has also been observed by Fraser et al. (2020).

\subsection{Multiparameter Conceptual Model}

A conceptual model based on observed different mechanical and hydraulic (MH) stages can be compiled. In Fig. 16, the temporal evolution of the pressurization rate is plotted against injection pressure and $\mathrm{AE}$ rate, from the moment $p_{\mathrm{inj}}$ is higher than $0.5 \mathrm{MPa}$, which marks the beginning of the borehole pressurization in BS8 and COS1, defining Stage 0 . Although borehole pressurization did not occur in BS7, for simplicity we keep $0.5 \mathrm{MPa}$ as starting level for all three experiments.

In BS7, Stage I (Fig. 16A and D) shows that the injection pressure as well as the pressurization rate remain low and AEs are recorded. The injection fluid permeates through the highly permeable rock spreading towards the edges of the sample, reached at the beginning of Stage II. Here, both the injection pressure and pressurization rate increase and $\mathrm{AE}$ are recorded only towards the end of this stage. The injection fluid has now reached the edges of the sample and is in 


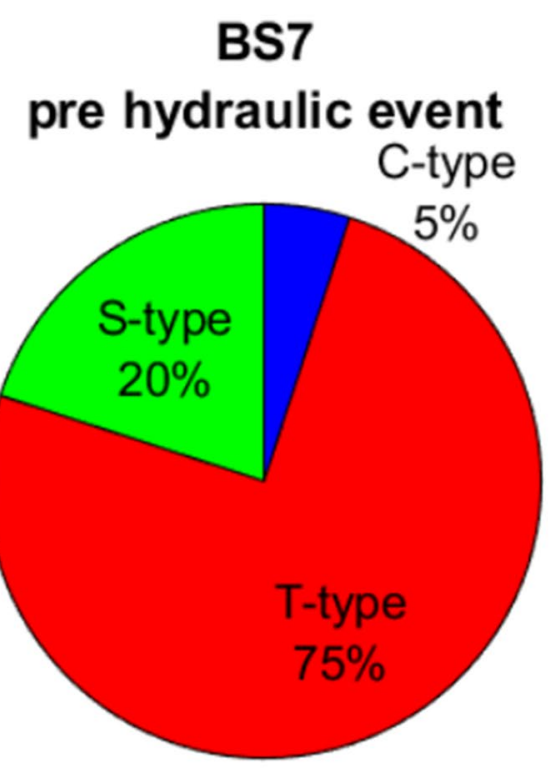

BS8

pre hydraulic event

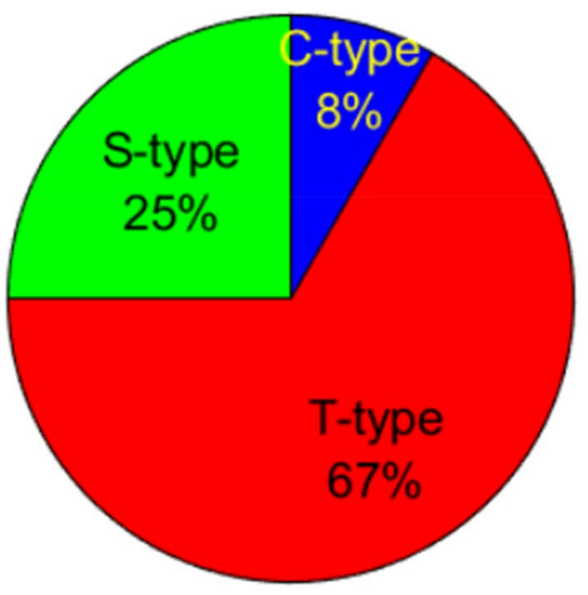

BS8 post hydraulic event

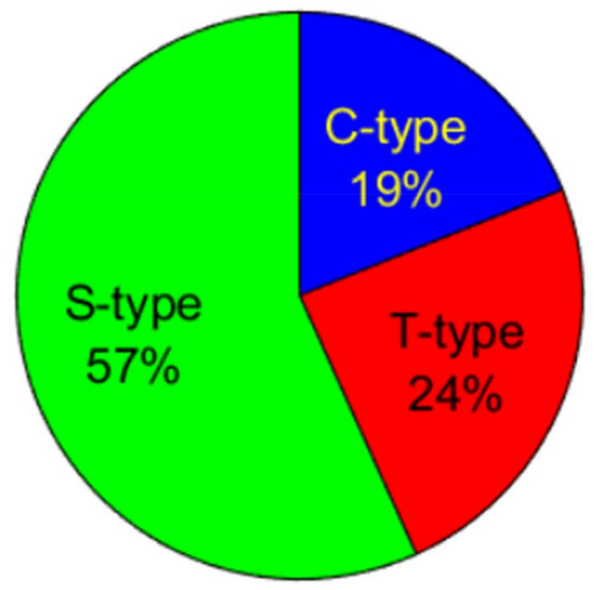

Fig. 10 Source-type pie chart for experiment BS7 (above) and BS8 (below)

direct contact with the impermeable outer sleeve, building up pressure until pressure equilibrium between injection and confining pressures is attained, marking Stage III. Injection pressure cannot increase any longer and no $\mathrm{AE}$ are recorded. Overall, due to the absence of an internal sleeve, the high permeability of BS controls the outcome during the entire experiment.

In BS8 Stage I (Fig. 16B and D), injection pressure increases and $\mathrm{AE}$ are recorded but the pressurization rate is neither linear, nor monotonic. Although the borehole is pressurized, the injection fluid still escapes through the inner sleeve, as indicated by the occurrence of AEs. Although this stage is affected by the SF mode, the high permeability of
BS still plays a role by letting the injection fluid through the rock matrix. At the end of Stage I there is a drastic reduction in permeability marked by the sudden increase in pressurization rate, which leads the injection pressure towards $P_{\mathrm{b}}$, and paucity of AE events, characterizing Stage II. Considering the well-sorted granulometry, the homogeneous distribution in porosity and permeability parameters, and the high rockmatrix permeability of $\mathrm{BS}$, and the absence of further AE recorded afterwards, we assume that this change in pressurization rate must be caused by a change in the sealing function of the inner sleeve, which is now basically impermeable. Therefore, Stage II is clearly affected by the SF mode. Once $P_{\mathrm{b}}$ occurs (Stage III), the pressurization rate recovers to 
Fig. 11 A Injection pressure (solid black line) and injected volume (solid blue line) plotted with cumulative AEs (red dots and line) and volumetric strain (dotted black line) for sample COS1. The lower-case letter indicates the time of the snapshot shown in Fig. 12. B Axial, NS and EW radial strain plotted together with $\mathrm{AE}$ rate. $\mathrm{C} 60 \mathrm{~s}$ zoom-in at $P_{\mathrm{b}}$ of plot A. The lower-case letters indicate the time of the snapshots shown in Figs. 12 and 13. D 60 s zoom-in at $P_{\mathrm{b}}$ of plot B (color figure online)
A)

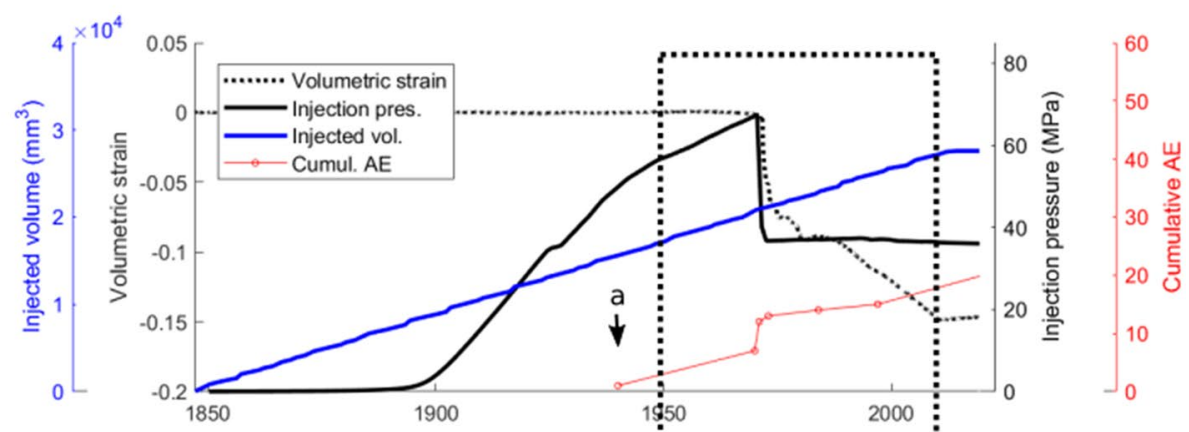

B)

C)

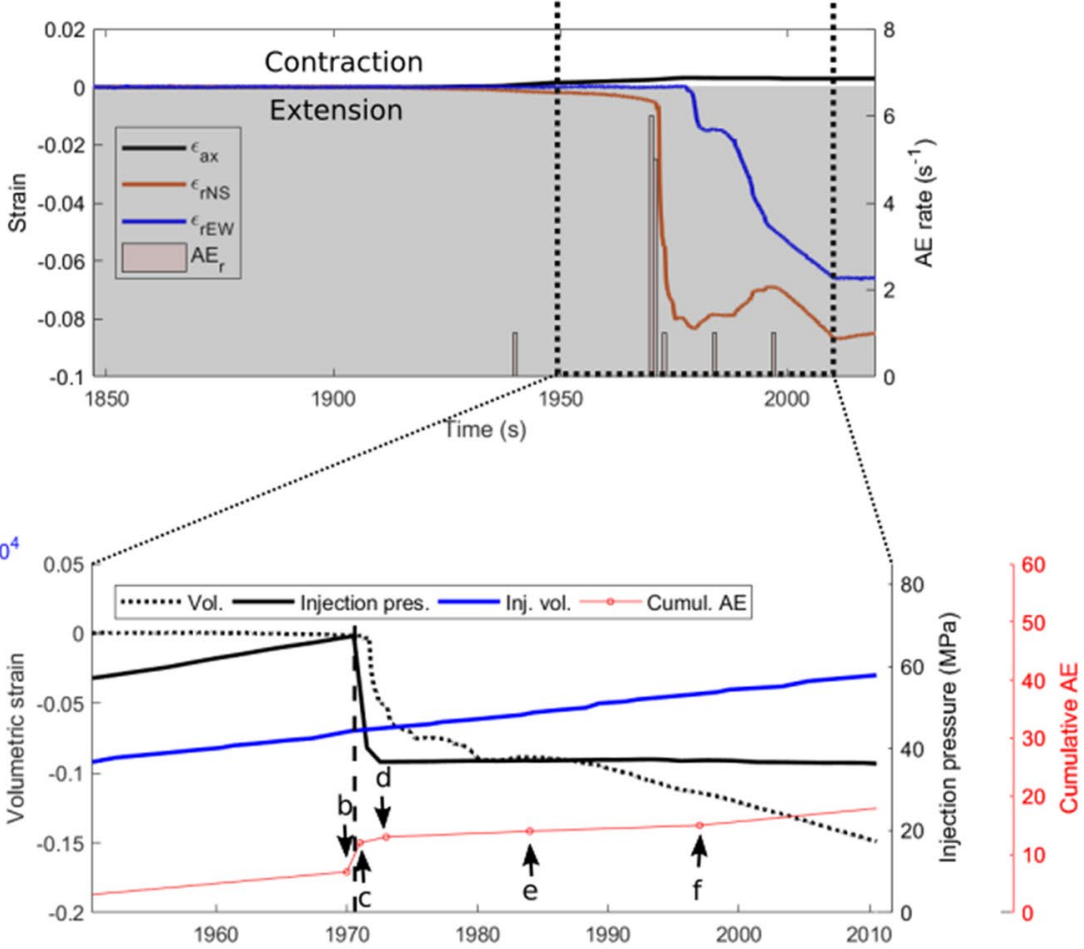

D)

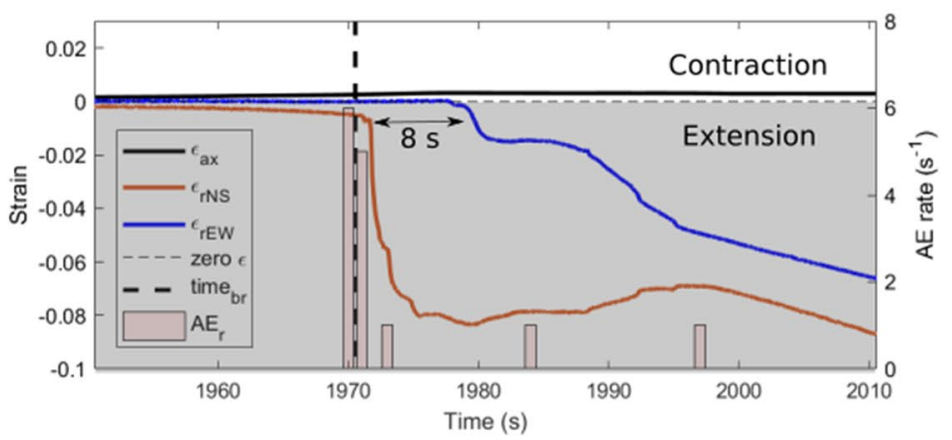

lower level and injection pressure continues to increase after the first stress drop. Here (see Fig. 9), fracturing occurs on both sides of the borehole, but these fractures are not fully developed. In addition, the formation of these cracks directly forms permeable features between the borehole and highly permeable rock matrix, leading to fluid leak-off (explaining the lower pressurization rate compared to Stage II). As discussed in Sect. 4.3, the fluid viscosity effect only appears immediately after breakdown, while afterwards the slower fracture propagation is affected by the high permeability 
Fig. 12 Spatial and temporal evolution of cumulative $\mathrm{AE}$ activity represented in $3 \mathrm{D}$ and plan view at selected snapshots (see Fig. 11A and C) of experiment COS1. In (a) only event recorded during the early stage. In (b), immediately before fracturing, six AEs are recorded. In (c), after fracturing, five more events occur. The size of the symbols represents a normalized relative magnitude a)
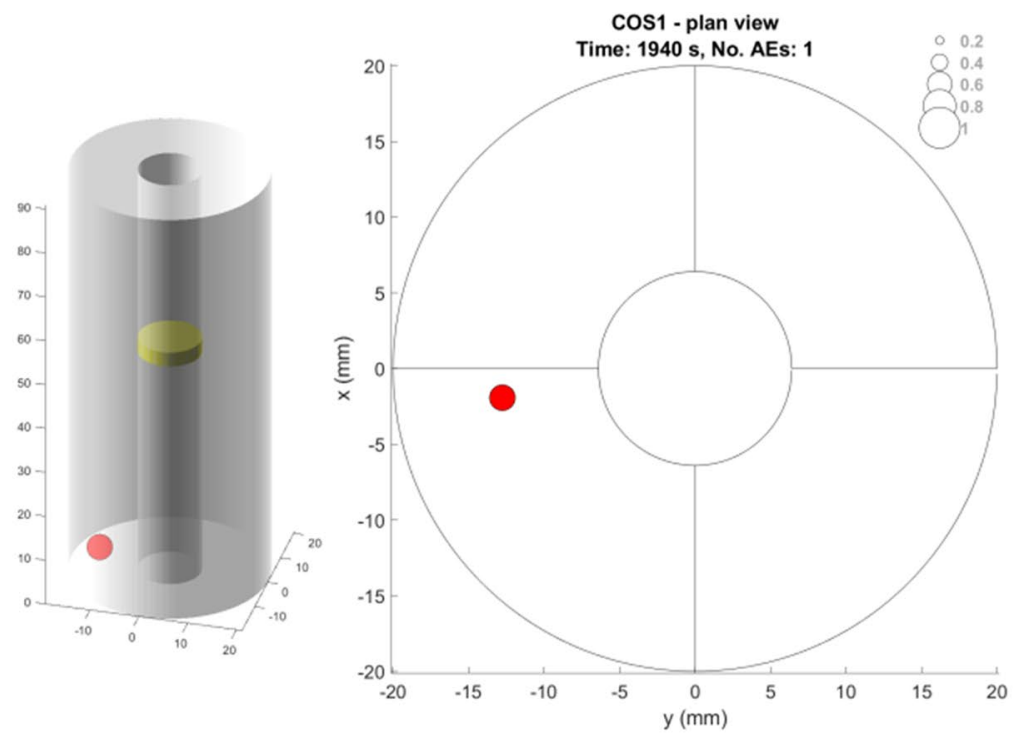

b)
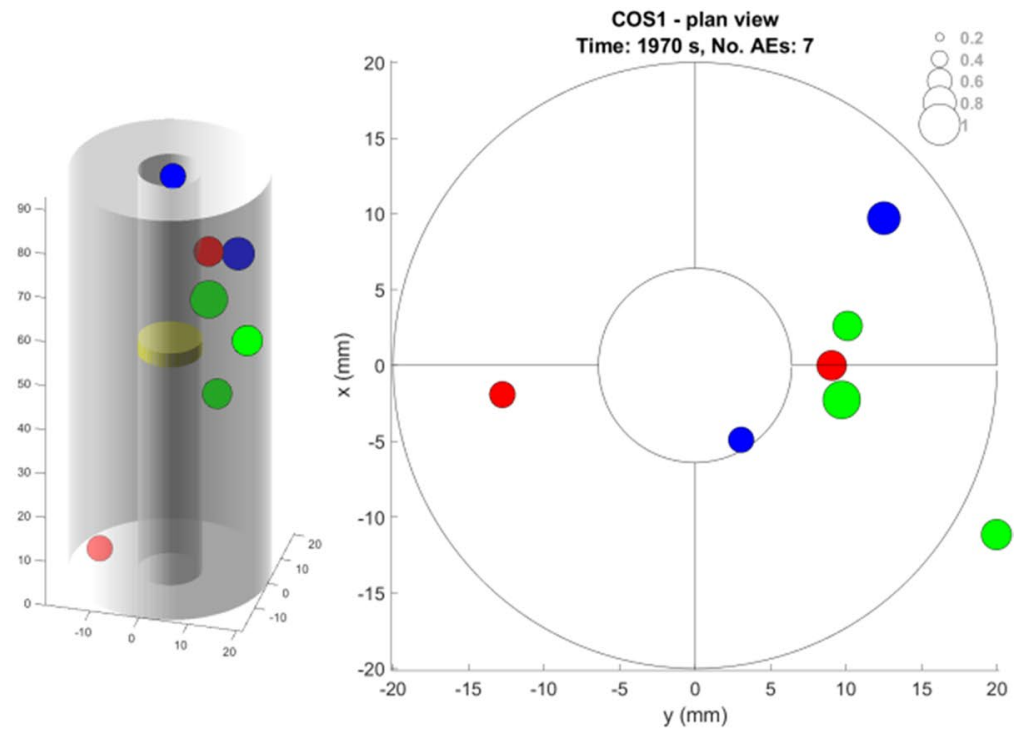

c)

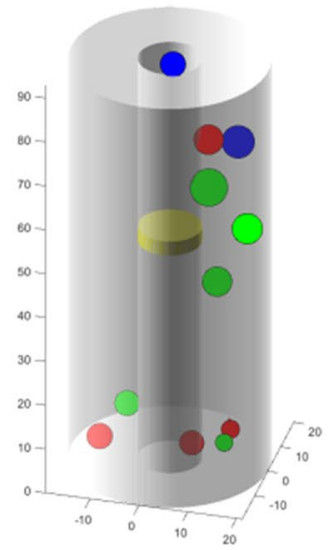


Fig. 13 Spatial and temporal evolution of cumulative AE activity represented in $3 \mathrm{D}$ and plan view at selected snapshots (see Fig. 11C) of experiment COS1. Only three events, at a high interval time, are recorded after the burst of AE associated to the pressure drop and are all S-type and all located in the east sector. The size of the symbols represents a normalized relative magnitude d)
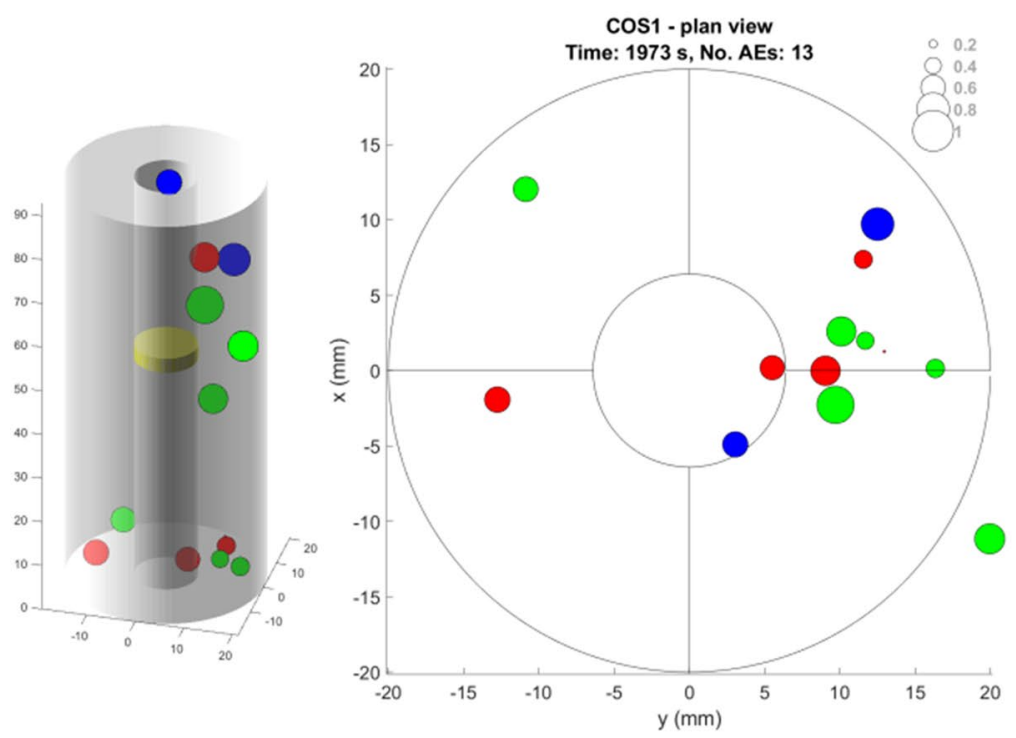

e)
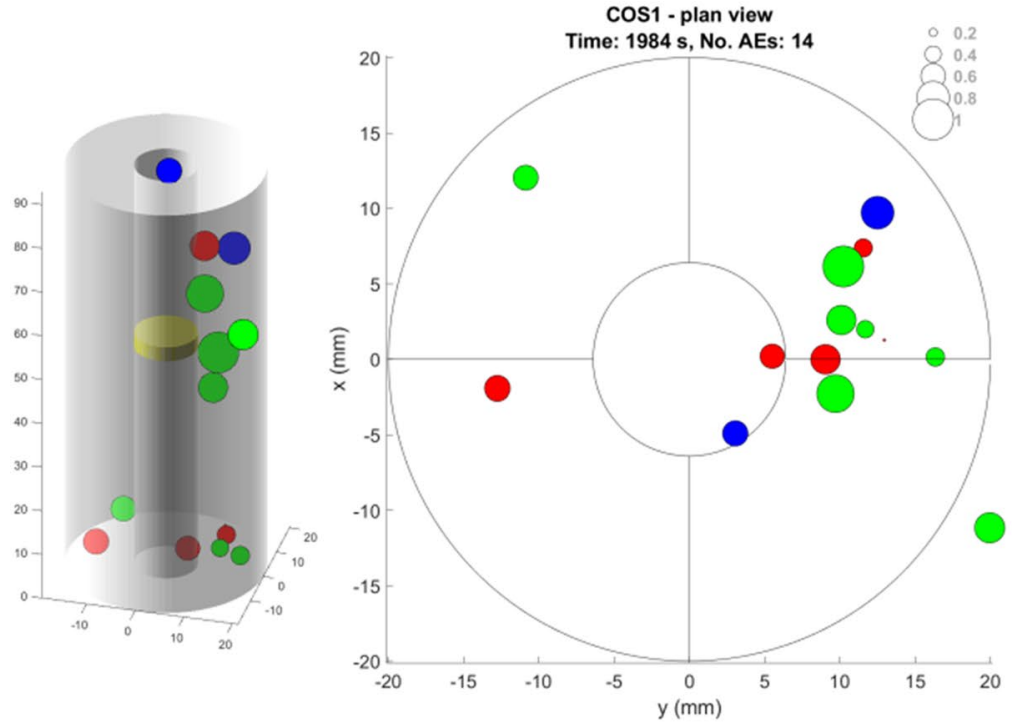

f)
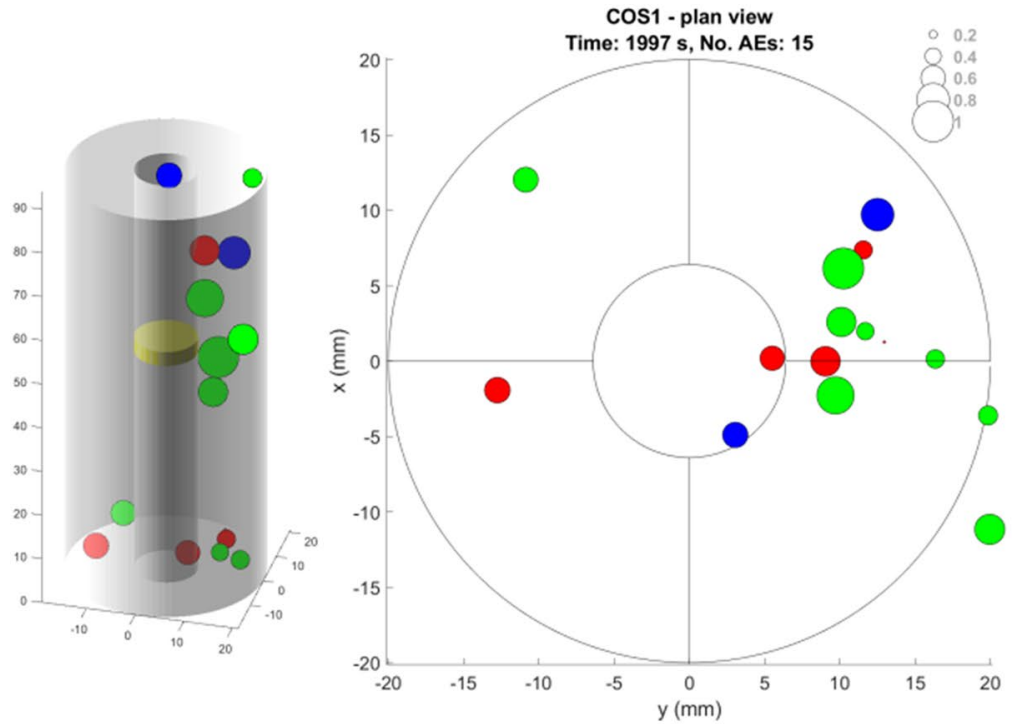


\section{cos1 \\ post hydraulic event}

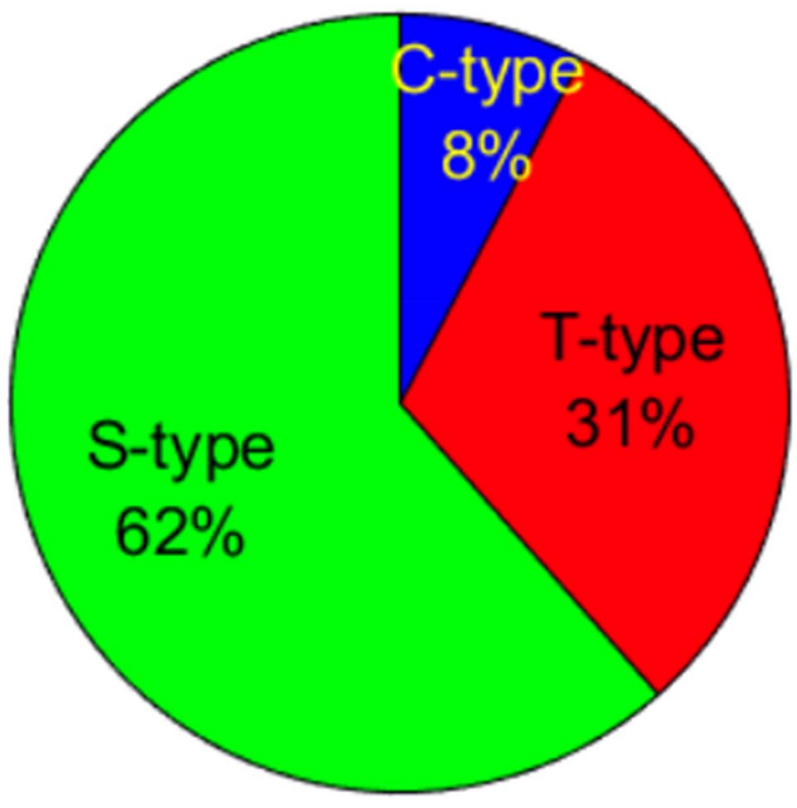

Fig. 14 Source-type pie chart for experiment COS1 occurring after $P_{\mathrm{b}}$. The majority of the AE event is S-type source (62\%), followed by T-type (19\%) and C-type (19\%)

of BS rock matrix. Stage IV, occurring ca. $18 \mathrm{~s}$ after $P_{\mathrm{b}}$, marks the formation of a fully developed SW fracture wing, accompanied by AE cluster and flowing of the injection fluid through the fracture towards the impermeable outer sleeve.

In COS1, Stage I (Fig. 16C and D), injection pressure builds up and the pressurization rate increases linearly up to half of the stage. This is followed by the flattening of the pressurization rate for about $20 \mathrm{~s}$, dramatically dropping at the end of this stage. However, no stress drop is visible nor any AE activity. In this stage, the low permeability of COS controls the pressurization outcome, with the injection fluids initially confined in the borehole. However, halfway of the stage the fluid leaks through it, likely through a nearby bedding plane, headed westward (as the only recorded AE suggests). This explains the drop in the pressurization rate as well as the absence of AE events. The slightly non-axial direction of the eventual fracture wing (Fig. 13) combined with the high anisotropy of the rock suggests that the fracturing process is anisotropy-controlled (Stoeckhert et al. 2015). During Stage II the pressurization rate briefly starts again to increase but after approximately $10 \mathrm{~s}$ it decreases once again, remaining at a low level compared to Stage I. At this point the injection fluid escapes more easily through the borehole and the newly activated pathway. Comparing BS 8 and COS1, it is noticeable that the sequence of highpressurization-rate stages are swapped: while in BS8 an initial fluid permeation through the borehole (and consequently low-pressurization rates) is followed by high pressurization rate possibly due to the reduced permeability of the inner sleeve, in COS1 a high pressurization rate is followed by late fluid permeation, likely to occur along a bedding plane.

However, the permeability of COS is not high enough to impede the pressure build-up, so hydraulic fracturing occurs (Stage III) accompanied by two clusters of AE events, the first one headed NE, the second one headed ESE (although there was no macroscopic evidence of the latter). While the initial fracture propagation is controlled by the fluid viscosity, discussed in Sect. 4.3, its subsequent development is likely a result of the presence and hydraulic function of bedding planes. The fracture fully develops in $8 \mathrm{~s}$ and injection fluid is able to flow through it reaching the impermeable outer sleeve. Pressure balance between injection and confining pressure marked the end of the experiment.

This analysis shows how permeability (both that of the rock matrix and that of the borehole wall), rock heterogeneities and, marginally, fluid viscosity all contribute to the hydraulic fracturing process, its eventual breakdown pressure and fracture propagation behavior.

Relating the results of this study to field hydraulic fracturing operations, here we proved that hydraulic fracturing in already high-permeable reservoirs is still feasible, and although the pre- and post-test permeability

Table 3 Mathematical equations quantifying major variable during hydraulic fracturing and estimated values of $P_{\mathrm{b}}$ for conditions used in BS8

\begin{tabular}{llll}
\hline Study & Equation for $P_{\mathrm{b}}$ & Information & Estimated $P_{\mathrm{b}}(\mathrm{MPa})$ \\
\hline Hubbert and Willis (1957) & $=3 S_{h}-S_{H}+\sigma_{T}-P_{0}$ & Linear elastic approach, impermeable & 71.9 \\
Haimson and Fairhurst (1969) & $=\frac{\left(3 S_{h}-S_{H}+\sigma_{T}\right)}{2-\alpha \frac{1-2 v}{1-\nu}}+\boldsymbol{P}_{0}$ & $\begin{array}{l}\text { Linear elastic approach with poroelastic } \\
\text { effects }\end{array}$ & $\mathbf{4 5 . 2 - 4 8 . 3}$ \\
Stoeckhert et al. (2014) & $=6 \sigma_{r}+\sigma_{T}$ & SF mode & 211.9 \\
Pradhan et al. (2015) & $=\frac{1}{1+q^{2}}\left[2 \sigma_{r}+\sigma_{T}\left(1-q^{2}\right)\right]$ & $\begin{array}{l}\text { Linear elastic approach; } \\
q=\frac{d_{\text {inner }}}{d_{\text {outer }}}\end{array}$ & 65 \\
Stoeckhert et al. (2016) & $=(6.6 \pm 1.1) \sigma_{r}+\sigma_{T}$ & SF mode & $194.4-271.4$ \\
\hline
\end{tabular}

The method that best estimates $\mathrm{P}_{\mathrm{b}}$ in bold 
Fig. 15 AE locations, shown parallel to the generated fracture in BS8 and COS1, during A a 30-s time window and $\mathbf{B}$ a zoom-in of $2.5 \mathrm{~s}$ around the time of breakdown

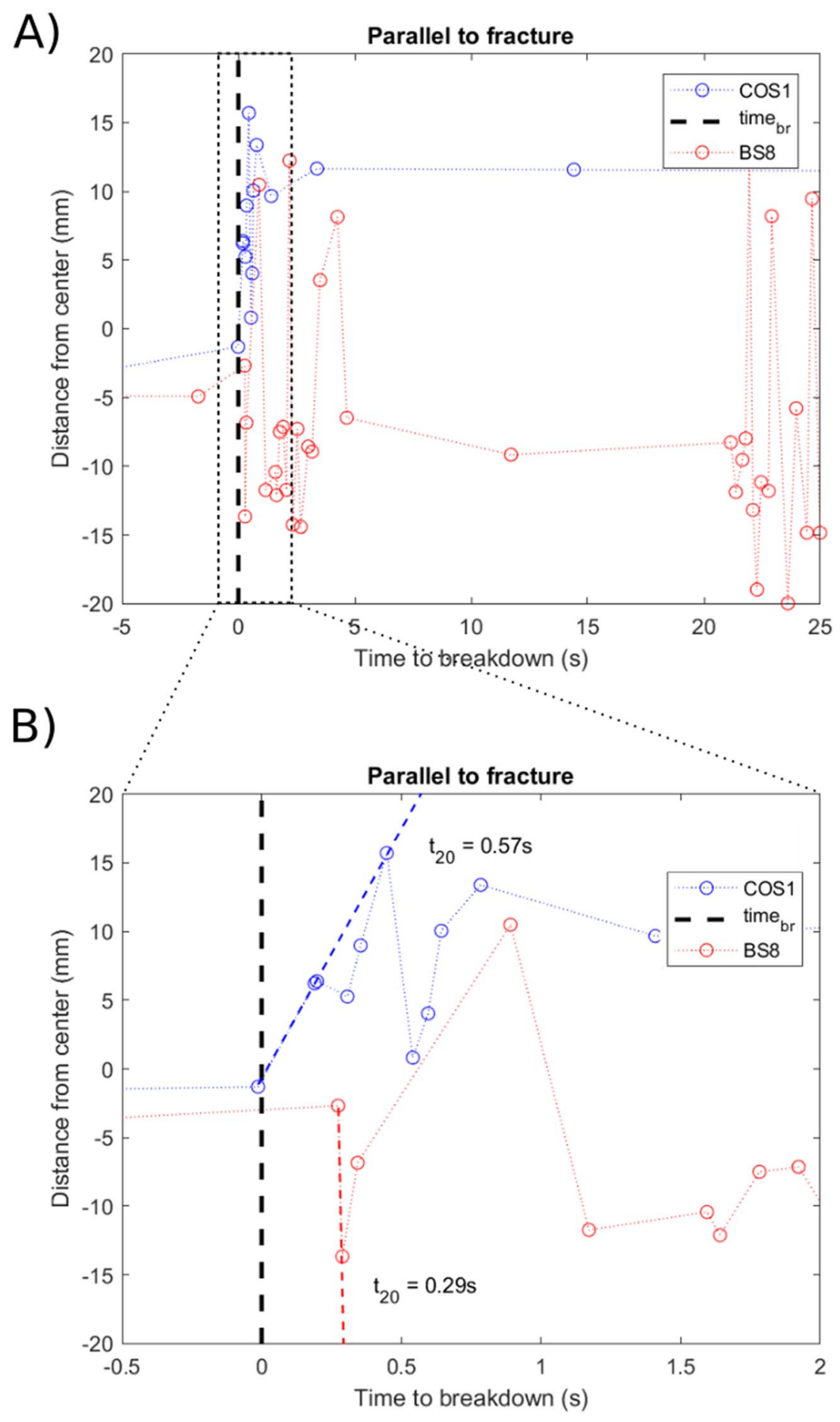

was not determined, we assume that we enhanced this by adding fracture permeability to the (high) matrix permeability. Most importantly, stress drop and induced seismicity did not increase manifolds and, therefore, the seismic risk will be similar to that one associated with hydraulic fracturing in reservoir of lower permeability. In addition, an early seismic swarm during fluid injection is more likely to be associated to fluid permeation through the rock matrix signaling an unsuccessful hydraulic fracturing operation. 
A)

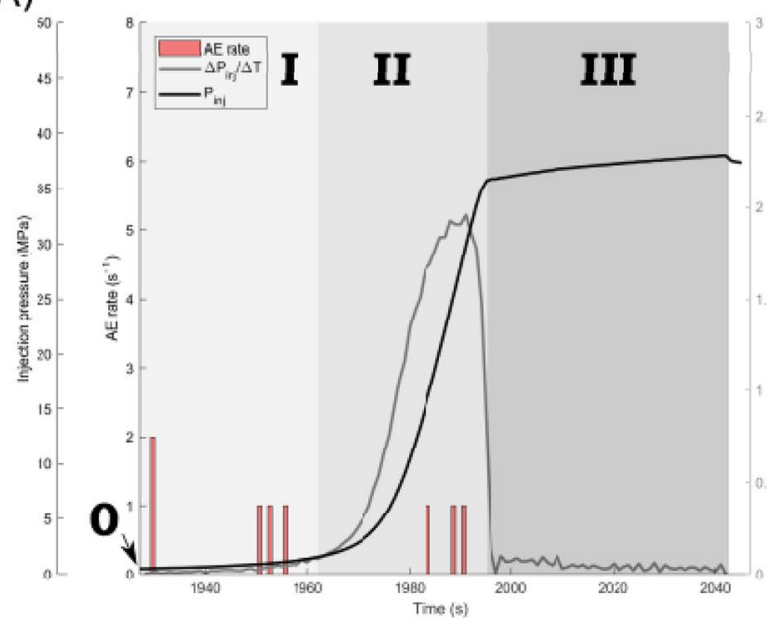

B)

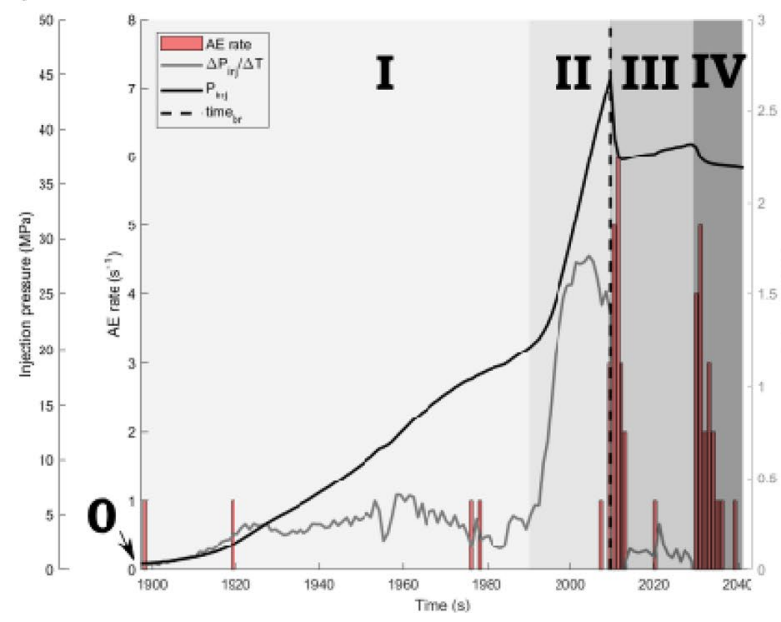

C)

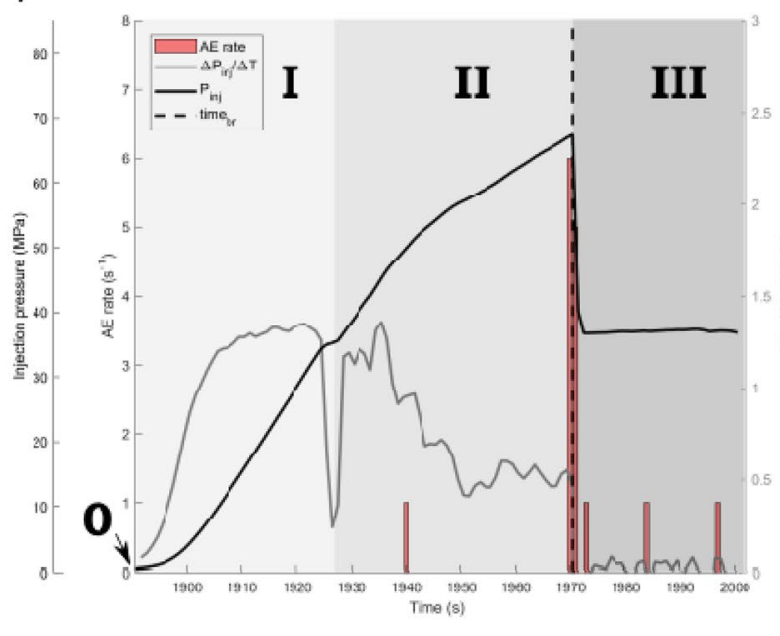

D)

Stage 0

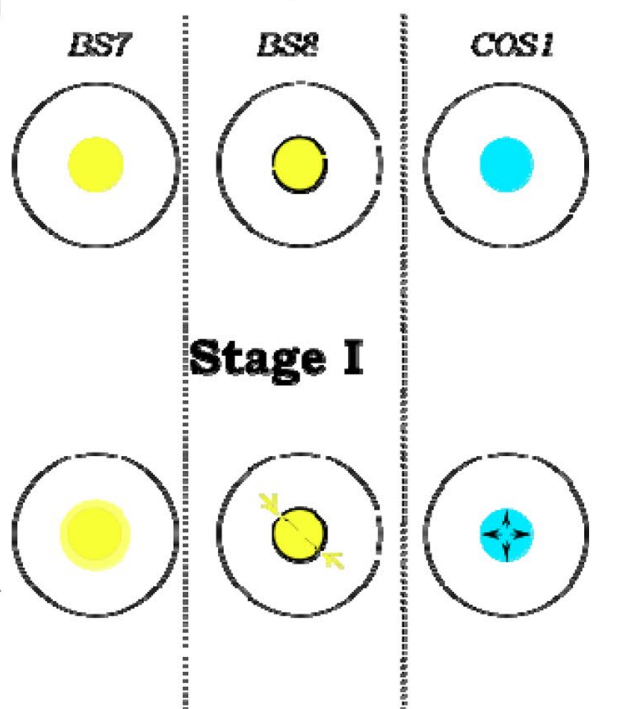

Stage II
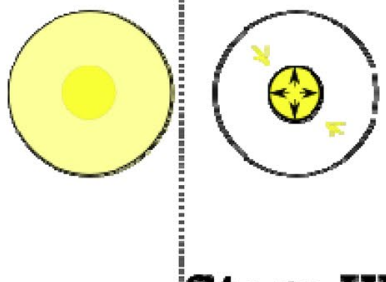

Stage III
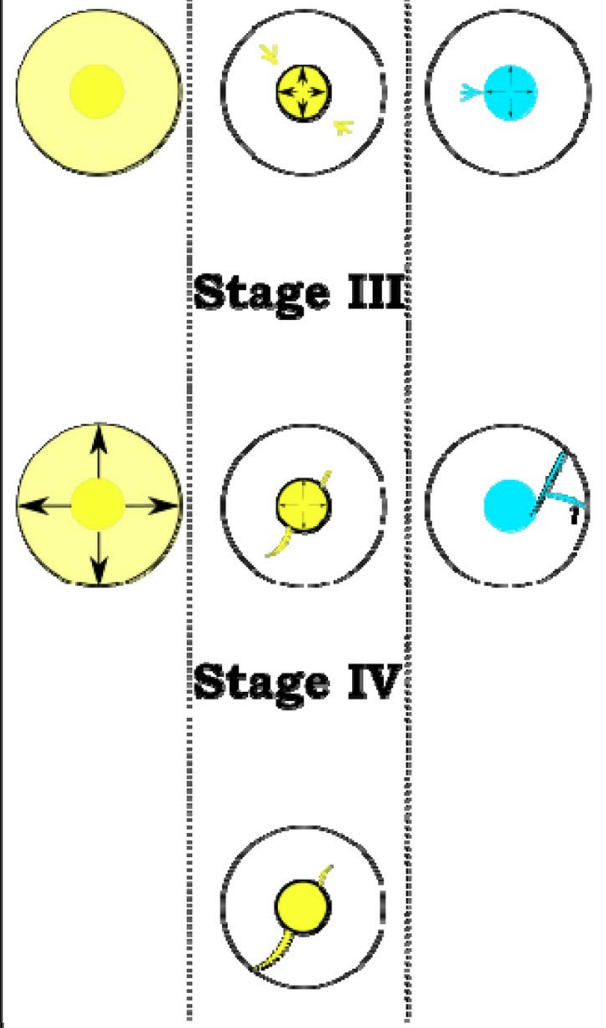

Fig. 16 Time series plot of pressurization rate, injection pressure and $\mathrm{AE}$ rate for A BS7, B BS8 and C COS1 observed from $p_{\text {inj }}=0.5 \mathrm{MPa}$ to the end of the injection phase. The different grey areas represent the $\mathrm{MH}$ stages described on the right. D Different MH stages char- acterizing the injection phase in BS7, BS8 and COS1. As fracture in BS8 does not develop continuously, but rather episodically, a further Stage IV is added 


\section{Conclusions}

In this study, laboratory experiments on small scale samples are performed and analyzed to understand the role of permeability in the hydraulic fracturing process. Three different scenarios are investigated: fluid fracturing (FF) in highly permeable Bentheim Sandstone, sleeve fracturing ( $\mathrm{SF}$, borehole skin) in the same material and fluid fracturing in lowly permeable Crab Orchard Sandstone. The goal was to induce hydraulic fracturing in a highly permeable rock, limiting the permeation of fluid through the rock matrix, but without increasing multiply the breakdown pressure and the AE activity as previous studies have shown. The application of a borehole sleeve (or skin) demonstrates field application as well as modes of achieving hydraulic fractures in highly permeable rock matrices.

Although hydraulic fracturing does not directly occur in the FF experiment in BS, as expected, the presence of an inner sleeve in the SF experiment impedes the escape of fluids from the borehole through the permeable rock matrix. Hydraulic fracturing occurs but breakdown pressure $\left(P_{\mathrm{b}}\right)$ does not increase substantially, but remains to a level that can be explained by a linear elastic approach considering poroelastic effects. The inner sleeve is shown not to be completely sealing off the borehole from the matrix, but it manages to reduce the wall permeability of the borehole to reach hydraulic fracturing, suggesting that $P_{\mathrm{b}}$ equations must consider the borehole permeability.

Precursory AEs are crucial to predict an eventual failure, but precursory activity is either low or absent when fracturing eventually occurs, while it is moderate when then level of fluid permeation inhibits fracturing. In addition, the precursory AE activity, mostly occurring at an early stage in the pressurization stage, is characterized by tensile sources. These combined information points to $\mathrm{AE}$ activity related to the leaking of fluids through permeable rock matrix and consequently pressurization and expansion of the pore space. The presence of moderate seismic activity, particularly at low level of pressurization, may reveal the level of fluid permeation and, therefore, the eventual success of the hydraulic fracturing process. Considering that hydraulic fracturing is difficult to predict, knowing a-priori whether fracturing occurs or not, constitutes a major step forward to avoid the side effect associated with the injection process (e.g. fluid permeation, induced seismicity), particularly when fracturing does not occur.

Once fracture occurs, rock matrix permeability also controls its propagation. We conclude that a fracture propagates fast and continuously in COS sample while it develops gradually and episodic in BS (in SF mode). The reason behind this is linked to the leak-off of the fluid from the newly created partial fracture through the adjacent permeable rock matrix, not anymore confined by the inner sleeve. Finally, we conclude that a number of key factors explain the mechanical and hydraulic processes involved in the generation (or not) of the hydraulic fracture, with matrix permeability being the most important.

Acknowledgements The authors acknowledge Emily Butcher and Ricardo Tomas for technical support in the Rock Mechanics Laboratory, and Dr. Stephan Gehne for thoughtful discussions. This research was funded by a Nds. MWK Forschungspoolstelle to Professor Martin Sauter and by a Petroleum Technology Development Fund (PTDF, Nigeria) to Peter Ibemesi during his PhD project. Finally, we would like to thank Guido Blöcher, Georg Dresen and an anonymous reviewer who, with their comments and suggestions, helped us to improve the quality of this manuscript.

Author Contributions MF wrote the manuscript and, together with PI, performed the experiments and analyzed the data. MF, PB and MS initiated the concept and developed the methods. DB-G carried out the microstructural analysis on the Bentheim sandstone. All authors provided intellectual input during the writing of the manuscript.

Funding Open Access funding enabled and organized by Projekt DEAL.

\section{Declarations}

Conflict of interest The authors declare no conflict of interest.

Open Access This article is licensed under a Creative Commons Attribution 4.0 International License, which permits use, sharing, adaptation, distribution and reproduction in any medium or format, as long as you give appropriate credit to the original author(s) and the source, provide a link to the Creative Commons licence, and indicate if changes were made. The images or other third party material in this article are included in the article's Creative Commons licence, unless indicated otherwise in a credit line to the material. If material is not included in the article's Creative Commons licence and your intended use is not permitted by statutory regulation or exceeds the permitted use, you will need to obtain permission directly from the copyright holder. To view a copy of this licence, visit http://creativecommons.org/licenses/by/4.0/.

\section{References}

Benson PM, Meredith PG, Platzman ES (2003) Relating pore fabric geometry to acoustic and permeability anisotropy in crab orchard sandstone: a laboratory study using magnetic ferrofluid. Geophys Res Lett 30(19):1976. https://doi.org/10.1029/2003GL017929

Benson PM, Meredith PG, Platzman ES, White RE (2005) Pore fabric shape anisotropy in porous sandstones and its relation to elastic wave velocity and permeability anisotropy under hydrostatic pressure. Int J Rock Mech Min Sci 42(7-8):890-899. https://doi.org/ 10.1016/j.ijrmms.2005.05.003

Benson PM, Meredith PG, Schubnel A (2006) Role of void space geometry in permeability evolution in crustal rocks at elevated pressure. J Geophys Res Solid Earth. https://doi.org/10.1029/ 2006JB004309 
Biot MA, Willis DG (1957) The elastic coeffkients of the theory of consolidation. J Appl Mech 594-601

Blöcher G, Reinsch T, Hassanzadegan A, Milsch H, Zimmermann G (2014) Direct and indirect laboratory measurements of poroelastic properties of two consolidated sandstones. Int J Rock Mech Min Sci 67:191-201. https://doi.org/10.1016/j.ijrmms.2013.08.033

Brenne S, Molenda M, Stockhert F, Alber M (2013) Hydraulic and sleeve fracturing laboratory experiments on 6 rock types. In: Jeffrey $\mathrm{R}$ (Ed.). Effective and sustainable hydraulic fracturing, pp. 425-436. InTech. Doi: https://doi.org/10.5772/56301

Chen Y, Naoi M, Tomonaga Y, Akai T, Tanaka H, Takagi S, Ishida T (2018) Method for visualizing fractures induced by laboratorybased hydraulic fracturing and its application to shale samples. Energies 11(8):1976. https://doi.org/10.3390/en11081976

Chitrala Y, Moreno C, Sondergeld CH, Rai CS (2011) Microseismic and microscopic analysis of laboratory induced hydraulic fractures. Canadian unconventional resources conference. Doi: https:// doi.org/10.2118/147321-MS

Dubelaar CW, Nijland TG (2016) Early Cretaceous Obernkirchen and Bentheim Sandstones from Germany used as dimension stone in the Netherlands: Geology, physical properties, architectural use and comparative weathering. Geol Soc Lond Spec Publ 416(1):163-181. https://doi.org/10.1144/SP416.13

Fazio M (2017) Dynamic laboratory simulations of fluid-rock coupling with application to volcano seismicity and unrest [Doctoral Thesis]. University of Portsmouth

Fazio M, Benson PM, Vinciguerra S (2017) On the generation mechanisms of fluid-driven seismic signals related to volcano-tectonics: experiments on Fluid-Induced Seismicity. Geophys Res Lett 44(2):734-742. https://doi.org/10.1002/2016GL070919

Fazio M, Alparone S, Benson PM, Cannata A, Vinciguerra S (2019) Genesis and mechanisms controlling tornillo seismo-volcanic events in volcanic areas. Sci Rep 9(1):7338. https://doi.org/10. 1038/s41598-019-43842-y

Fraser AP, McDermott CI, Couples GD, Edlmann K, Lightbody A, Cartwright A, Kendrick JE, Brondolo F, Fazio M, Sauter M (2020) Experimental investigation of hydraulic fracturing and stress sensitivity of fracture permeability under changing polyaxial stress conditions. J Geophys Res 125:e2020JB020044

Gehne S, Benson PM (2017) Permeability and permeability anisotropy in Crab Orchard sandstone: experimental insights into spatio-temporal effects. Tectonophysics 712-713:589-599. https://doi.org/ 10.1016/j.tecto.2017.06.014

Gehne S, Benson PM (2019) Permeability enhancement through hydraulic fracturing: Laboratory measurements combining a 3D printed jacket and pore fluid over-pressure. Sci Rep 9(1):12573. https://doi.org/10.1038/s41598-019-49093-1

Gehne S, Benson PM, Koor N, Dobson KJ, Enfield M, Barber A (2019) Seismo-mechanical response of anisotropic rocks under hydraulic fracture conditions: new experimental insights. J Geophys Res Solid Earth 124(9):9562-9579. https://doi.org/10.1029/2019J B017342

Gehne S, Forbes Inskip ND, Benson PM, Meredith PG, Koor N (2020) Fluid-driven tensile fracture and fracture toughness in nash point shale at elevated pressure. J Geophys Res Solid Earth. https://doi. org/10.1029/2019JB018971

Ghaderi A, Taheri-Shakib J, Sharifnik MA (2019) The effect of natural fracture on the fluid leak-off in hydraulic fracturing treatment. Petroleum 5(1):85-89. https://doi.org/10.1016/j.petlm.2018.05. 006

Ha SJ, Yun TS, Kim KY, Jung SG (2017) Experimental study of pumping rate effect on hydraulic fracturing of cement paste and mortar. Rock Mech Rock Eng 50(11):3115-3119. https://doi.org/10.1007/ s00603-017-1276-1

Ha SJ, Choo J, Yun TS (2018) Liquid CO2 Fracturing: effect of fluid permeation on the breakdown pressure and cracking behavior.
Rock Mech Rock Eng 51(11):3407-3420. https://doi.org/10.1007/ s00603-018-1542-x

Haimson B, Fairhurst C (1969) In-situ stress determination at great depth by means of hydraulic fracturing. The 11 th US symposium on rock mechanics (USRMS), 26

He J, Lin C, Li X, Wan X (2016) Experimental investigation of crack extension patterns in hydraulic fracturing with shale, sandstone and granite cores. Energies 9(12):1018. https://doi.org/10.3390/ en9121018

Hubbert MK, Willis DG (1957) Mechanics of hydraulic fracturing. Trans AIME 210:39-257

Ishida T, Chen Q, Mizuta Y, Roegiers J-C (1998) Influence of fluid viscosity on hydraulically induced crack geometry. Int J Rock Mech Min Sci 35(4-5):460-462. https://doi.org/10.1016/S01489062(98)00046-1

Ito T, Hayashi K (1991) Physical background to the breakdown pressure in hydraulic fracturing tectonic stress measurements. Int $\mathbf{J}$ Rock Mech Min Sci Geomech Abstr 28(4):285-293

Jaeger JC, Cook NGW, Zimmerman RW (2009) Fundamentals of rock mechanics, 4th edn. Blackwell Publishing, Hoboken

Jasinski L, Sangaré D, Adler PM, Mourzenko VV, Thovert J-F, Gland N, Békri S (2015) Transport properties of a Bentheim sandstone under deformation. Phys Rev E 91(1):013304. https://doi.org/ 10.1103/PhysRevE.91.013304

Lin C, He J, Li X (2018) Width evolution of the hydraulic fractures in different reservoir rocks. Rock Mech Rock Eng 51(5):16211627. https://doi.org/10.1007/s00603-017-1391-z

Lockner D, Byerlee JD (1977) Hydrofracture in Weber sandstone at high confining pressure and differential stress. J Geophys Res 82(14):2018-2026

Ma X, Haimson BC (2016) Failure characteristics of two porous sandstones subjected to true triaxial stresses. J Geophys Res Solid Earth 121(9):6477-6498. https://doi.org/10.1002/2016J B012979

Majer EL, Baria R, Stark M, Oates S, Bommer J, Smith B, Asanuma H (2007) Induced seismicity associated with enhanced geothermal systems. Geothermics 36(3):185-222. https://doi.org/10.1016/j. geothermics.2007.03.003

Meng C, De Pater HJ (2011) Hydraulic fracture propagation in prefractured natural rocks. SPE hydraulic fracturing technology conference. SPE hydraulic fracturing technology conference, The Woodlands, Texas, USA. Doi: https://doi.org/10.2118/140429-MS

Molenda M, Stockhert F, Brenne S, Alber M (2013) Comparison of hydraulic and conventional tensile strength tests. In: Jeffrey R (ed) Effective and sustainable hydraulic fracturing. InTech, USA. https://doi.org/10.5772/56300

Molenda M, Stoeckhert F, Brenne S, Alber M (2015) Acoustic emission monitoring of laboratory scale hydraulic fracturing experiments

Naoi M, Chen Y, Nishihara K, Yamamoto K, Yano S, Watanabe S, Morishige Y, Kawakata H, Akai T, Kurosawa I, Ishida T (2018) Monitoring hydraulically-induced fractures in the laboratory using acoustic emissions and the fluorescent method. Int J Rock Mech Min Sci 104:53-63. https://doi.org/10.1016/j.ijrmms.2018.02.015

Nelder JA, Mead R (1965) A simplex method for function minimization. Comput J 7(4):308-313. https://doi.org/10.1093/comjnl/7.4. 308

Peksa AE, Wolf K-HAA, Zitha PLJ (2015) Bentheimer sandstone revisited for experimental purposes. Mar Pet Geol 67:701-719. https:// doi.org/10.1016/j.marpetgeo.2015.06.001

Pimienta L, Borgomano JVM, Fortin J, Guéguen Y (2017) Elastic dispersion and attenuation in fully saturated sandstones: role of mineral content, porosity, and pressures. J Geophys Res Solid Earth 122(12):9950-9965. https://doi.org/10.1002/2017JB014645

Pradhan S, Stroisz AM, Fjær E, Stenebråten JF, Lund HK, Sønstebø EF, Roy S (2014) Fracturing tests on reservoir rocks: analysis of $\mathrm{AE}$ events and radial strain evolution. American Rock Mechanics 
Association. 48th US rock mechanics/geomechanics symposium, Minneapolis, MN, USA

Pradhan S, Stroisz AM, Fjær E, Stenebråten JF, Lund HK, Sønstebø EF (2015) Stress-induced fracturing of reservoir rocks: acoustic monitoring and $\mu \mathrm{CT}$ image analysis. Rock Mech Rock Eng 48(6):2529-2540. https://doi.org/10.1007/s00603-015-0853-4

Rück M, Rahner R, Sone H, Dresen G (2017) Initiation and propagation of mixed mode fractures in granite and sandstone. Tectonophysics 717:270-283. https://doi.org/10.1016/j.tecto.2017.08.004

Rummel F (1987) Fracture mechanics approach to hydraulic fracturing stress measurements. Fracture mechanics of rocks. Academic Press Inc, London, pp 217-240

Saenger EH, Lebedev M, Uribe D, Osorno M, Vialle S, Duda M, Iglauer S, Steeb H (2016) Analysis of high-resolution X-ray computed tomography images of Bentheim sandstone under elevated confining pressures: high-resolution X-ray CT images. Geophys Prospect 64(4):848-859. https://doi.org/10.1111/1365-2478. 12400

Sammonds PR (1999) Understanding the fundamental physics governing the evolution and dynamics of the Earth's crust and ice sheets. Philos Trans R Soc Lond 357:3377-3401

Song I, Suh M, Won KS, Haimson B (2001) A laboratory study of hydraulic fracturing breakdown pressure in tablerock sandstone. Geosci J 5(3):263-271. https://doi.org/10.1007/BF02910309

Stanchits S, Surdi A, Gathogo P, Edelman E, Suarez-Rivera R (2014) Onset of hydraulic fracture initiation monitored by acoustic emission and volumetric deformation measurements. Rock Mech Rock Eng 47(5):1521-1532. https://doi.org/10.1007/ s00603-014-0584-y

Stanchits S, Burghardt J, Surdi A (2015) Hydraulic fracturing of heterogeneous rock monitored by acoustic emission. Rock Mech Rock Eng 48(6):2513-2527. https://doi.org/10.1007/ s00603-015-0848-1

Stoeckhert F, Brenne S, Molenda M, Alber M (2014) Fracture mechanical evaluation of hydraulic fracturing laboratory experiments. In: Alejano L, Perucho Á, Olalla C, Jiménez R (eds) Rock engineering and rock mechanics: structures in and on rock masses.
CRC Press, Boca Raton, pp 1335-1340. https://doi.org/10.1201/ b16955-232

Stoeckhert F, Molenda M, Brenne S, Alber M (2015) Fracture propagation in sandstone and slate-laboratory experiments, acoustic emissions and fracture mechanics. J Rock Mech Geotech Eng 7(3):237-249. https://doi.org/10.1016/j.jrmge.2015.03.011

Stoeckhert F, Brenne S, Molenda M, Alber M (2016) Mode I fracture toughness of rock under confining pressure. Rock Mech Rock Eng past Future. https://doi.org/10.1201/9781315388502-52

Stück H, Koch R, Siegesmund S (2013) Petrographical and petrophysical properties of sandstones: statistical analysis as an approach to predict material behaviour and construction suitability. Environ Earth Sci 69(4):1299-1332. https://doi.org/10.1007/ s12665-012-2008-1

Vinciguerra S, Meredith PG, Hazzard J (2004) Experimental and modeling study of fluid pressure-driven fractures in Darley Dale sandstone. Geophys Res Lett. https://doi.org/10.1029/2004GL019638

Yao B, Wang L, Yin X, Wu Y-S (2017) Numerical modeling of cryogenic fracturing process on laboratory-scale Niobrara shale samples. J Nat Gas Sci Eng 48:169-177. https://doi.org/10.1016/j. jngse.2016.10.041

Zang A, Christian Wagner F, Stanchits S, Dresen G, Andresen R, Haidekker MA (1998) Source analysis of acoustic emissions in Aue granite cores under symmetric and asymmetric compressive loads. Geophys J Int 135(3):1113-1130. https://doi.org/10.1046/j.1365246X.1998.00706.x

Zhuang L, Kim KY, Jung SG, Diaz M, Min K-B (2018) Effect of Water Infiltration, Injection Rate and Anisotropy on Hydraulic Fracturing Behavior of Granite. Rock Mech Rock Eng. https://doi.org/ 10.1007/s00603-018-1431-3

Publisher's Note Springer Nature remains neutral with regard to jurisdictional claims in published maps and institutional affiliations. 